\title{
IDENTIDADE CIENTÍFICA E POPULAÇÕES NATIVAS: PERSPECTIVAS COMPARADAS ENTRE ARGENTINA, BRASIL E PERU (1950-2015) ${ }^{1}$
}

\author{
Narciso Leandro Xavier Baez ${ }^{2}$ \\ Thaís Janaina Wenczenovicz ${ }^{3}$
}

\begin{abstract}
Resumo
O presente trabalho objetiva traçar um estudo comparativo entre a produção científica em Cursos de PósGraduação em Direito tendo como objeto de pesquisa as dissertações e teses que possuem como temática de análise as populações nativas e comunidades tradicionais. Foram contempladas para fins de recorte três Universidades públicas e privada localizadas na Argentina, Brasil e Peru, tendo como delimitação temporal o período de 1950-2015. O procedimento metodológico utilizado é o analítico-interpretativo de investigação também inserindo elementos da legislação como os documentos internacionais internalizados, em especial a Convenção no. 169 da Organização Internacional do Trabalho (OIT) sobre os Povos Indígenas e Tribais, acrescido a pesquisa de campo - bibliotecas (acervo digital e físico) da Universidade de Buenos Aires - Faculdade de Direito/Argentina, Universidade Federal de Santa Catarina/Brasil e Universidade Nacional Mayor de San Marcos e Pontifícia Universidade de Lima/Peru.
\end{abstract}

Palavras-Chave: Argentina; Brasil; Identidade; Peru; Populações Nativas; Produção Científica.

\section{INTRODUÇÃO}

Nas três últimas décadas do século XX os povos nativos vêm ocupando espaços nos debates acadêmicos e também em organismos internacionais, como a ONU, por meio da comissão de Direitos Humanos, dos grupos de trabalho e do Fórum Permanente da ONU para os Povos Indígenas. ${ }^{4}$ Tal movimentação pode ser vista como

\footnotetext{
${ }^{1}$ A devida pesquisa que constitui a elaboração do artigo insere-se no Projeto de Pesquisa Direitos Fundamentais Civis: a ampliação dos direitos subjetivos no Programa de Pós-Graduação em Direito/UNOESC.

2 Coordenador Acadêmico-Científico do Centro de Excelência em Direito e do Programa de Mestrado em Direito da Universidade do Oeste de Catarina; Pós-Doutor em Mecanismos de Efetividade dos Direitos Fundamentais pela Universidade Federal de Santa Catarina. E-mail: narciso.baez@gmail.com

${ }^{3}$ Docente Adjunta e Pesquisadora Sênior na Universidade Estadual do Rio Grande do Sul. E-mail: t.wencze@terra.com.br

${ }^{4}$ Segundo as estimativas da ONU (2015), há mais de 370 milhões de pessoas indígenas em cerca de 70 países do mundo. Embora provenham de meios geográficos e culturais muito diversos, partilham problemas comuns: falta de cuidados de saúde básicos, acesso limitado à educação, falta de controlo sobre as suas terras, pobreza extrema, deslocação de populações, violações dos direitos humanos e marginalização social e econômica.
} 
elemento integrado ao processo de revisão identitária ${ }^{5}$ e conceitual na América Latina, momento o qual os povos originários têm readquirido o espaço que lhe foi privado desde os tempos coloniais.

Dessa disputa por espaço e sobrevivência obtém-se duas imagens marcantes: de um lado, a árdua luta contra o colonizador para se proteger, preservar a sua cultura e o seu território e, de outro, um povo submisso e indolente, que em troca de alguns presentes aceitou a presença dos colonizadores em seu território, entregandothes suas riquezas e abraçando a cultura civilizacionista. ${ }^{6}$

Em ambas as imagens que se espalharam no imaginário contemporâneo, há um componente comum: a quase extinção do povo nativo latino-americano, seja ela física ou etnocultural. No primeiro caso, a população indígena, predominante na região nos tempos da colonização, hoje representa cerca de $10 \%$ da população latinoamericana. Essa se encontra concentrada principalmente em cinco países: Bolívia, Equador, Guatemala, México e Peru. ${ }^{7}$ No segundo caso, os nativos latino-americanos passaram por um processo de aculturação tão significativo que dificilmente pode-se falar hoje de etnias e culturas indígenas autênticas. Muito se perdeu de sua identidade tendo em vista a eliminação de grupos humanos inteiros, passando pelo processo de aldeamento, aculturação e assimilação.

Em virtude da exploração colonial, os indígenas perderam suas referências materiais/estruturais - terras, fonte de sua sobrevivência e imateriais - aspectos artísticos, linguísticos e religiosos. A soma desses elementos indicou a chegada da pobreza e acarretou a deterioração da sua condição de vida, colocando-os em uma condição de exclusão e marginalização social. Em alguns países, como no Brasil, o Estado demarcou terras indígenas em todo o território nacional, na tentativa de lhes garantir a subsistência. No entanto, em muitos casos, o limite da exclusão aproxima-se do mínimo enquanto dignidade humana.

A problemática aqui estudada decorre do fato da diversidade - posta enquanto desafio da educação contemporânea - identificar a tensão existente entre a pluralidade étnico-cultural e a política de justiça universal. O reconhecimento e a valorização das identidades culturais, pelo desenvolvimento do multiculturalismo, permite que algumas categorias de indivíduos saiam de inicial isolamento para encontrar atenção e foco na análise multicultural.

\footnotetext{
${ }^{5}$ Para esse estudo adota-se o conceito de identidade de Anibal Quijano. QUIJANO, Anibal. Notas sobre a questão da identidade e nação no Peru. In: Revista estudos Avançados, São Paulo, v.6 (16), 1992.

${ }^{6}$ Para essa temática ver: RIBEIRO, Darcy. O povo brasileiro: a formação e o sentido do Brasil. São Paulo, Companhia das Letras, 1995; FERREIRA, Andrey Cordeiro. Tutela e Resistência indígena - etnografia e história das relações de poder entre os Terena e o Estado brasileiro, Tese (Doutorado), Rio de Janeiro, PPGAS-MN, UFRJ, 2007. TODOROV, Tzvetan. A conquista da América: a questão do outro. São Paulo: Martins Fontes, 2003.

${ }^{7}$ Nesta região, as estimativas avaliam que a população de indígenas oscila entre 8 a $12 \%$, o equivalente entre 30 e 50 milhões de pessoas, acumulando altos índices de mortalidade, analfabetismo e incidência de extrema pobreza (CEPAL, 2006a, 2006b; PNUD, 2004).
} 
Ademais, é o multiculturalismo que consente diferentes experiências derivadas do saber local, que devem ser dispostas e consideradas na construção dos currículos, sem perder de vista a dimensão universal da educação. Assim, as práticas curriculares devem ser baseadas no reconhecimento e na valorização da diversidade cultural.

É neste diapasão que surge o questionamento sobre as práticas pedagógicas ortodoxas e os discursos curriculares homogeneizantes ou etnocêntricos. Assim, esse ensaio não pretende desenvolver um plano teórico, mas sim uma amostragem para identificar, na produção acadêmica em nível de Pós-Graduação stricto sensu, a temática, junto a produção científica da área jurídica.

O devido artigo divide-se em quatro partes. A primeira parte intitulada 'Populações Nativas: reflexões Iniciais', tece considerações sobre o processo de ressignificação das comunidades nativas em perspectivas a produção científica. A segunda parte tem por objetivo apresentar um breve escorço da produção científica em nível de Pós-Graduação no Brasil, delimitando-se posteriormente a Universidade Federal de Santa Catarina junto ao Programa de Pós-Graduação em Direito/UFSC. A terceira parte denominada ‘Comunidades Nativas na Argentina e a produção científica' indica um breve histórico da Universidade de Buenos Aires/UBA e sua produtividade tendo por objeto central as populações indígenas. A última parte destina-se mapear os trabalhos em nível de Pós-Graduação no Peru, mais especificamente a Faculdade de Direito (Universidade Nacional Mayor de San Marcos e Pontifícia Universidade de Lima/Peru) que se propõem a estudar as populações nativas.

O procedimento metodológico utilizado é o analítico-interpretativo de investigação inserindo elementos como os documentos internacionais internalizados, em especial a Convenção no. 169 da Organização Internacional do Trabalho (OIT) sobre os Povos Indígenas e Tribais e a documentação pedagógica e a legislação interna das Universidades tais como: regimentos internos, projetos políticos pedagógicos e repositório de dissertações e teses. Acrescenta-se também na elaboração do trabalho a pesquisa de campo - bibliotecas (acervo digital e físico) da Universidade de Buenos Aires - Faculdade de Direito/Argentina, ${ }^{8}$ Universidade Federal de Santa Catarina/Brasil e Universidade Nacional Mayor de San Marcos e Pontifícia Universidade de Lima/Peru. ${ }^{9}$

\section{POPULAÇÕES NATIVAS: REFLEXÕES INICIAIS}

Inicialmente, faz-se indispensável analisar os conceitos “índio" e "indígena”, pois é importante ter claro que esses foram invenções do colonizador europeu quando da chegada as Américas. Historicamente, a ideia de que há raças humanas distintas não existia até o início da colonização, ou seja, está intimamente ligada ao

\footnotetext{
${ }^{8}$ Pesquisa realizada no período de 18 a 25 de janeiro de 2016, Buenos Aires/UBA - Faculdade de Derecho.

${ }^{9}$ Pesquisa realizada no período de 16 a 18 de outubro de 2015, Lima/PUCP.
} 
surgimento da modernidade (QUIJANO, 2005, p. 228). O conceito de raça surge para hierarquicamente distinguir o europeu dos povos ameríndios e posteriormente também para os diferenciarem dos povos africanos. ${ }^{10}$

O termo "índio" ou "indígena" abarcou e continua a abarcar uma quantidade bastante ampla de povos distintos. Com total propriedade abordou esse tema o primeiro indígena a se tornar mestre em Antropologia Social no Brasil, Gersem dos Santos Luciano-Baniwa, ao afirmar que as diferenças entre os povos indígenas não são apenas uma questão de tempo e de população, “(...), mas principalmente de cultura, de espírito e de visão do mundo sobre o passado, o presente e o futuro." (LUCIANO, 2006, p.17). Como o antropólogo bem analisou, ainda que em um primeiro momento o termo índio tenha surgido através de uma concepção apologética da história e, este é um conceito que sempre foi e continua sendo uma denominação genérica e ampla para àqueles povos que habitavam o continente americano há milhares de anos (LUCIANO, 2006, p.27-30).

Sem dúvida é fundamental reconhecer que o conceito de raça ${ }^{11}$ circunda o ideário de uma invenção moderna que conflui a questões relacionadas a hierarquizar e até estigmatizar, e que o termo "índio" foi uma denominação dada pelos europeus aos milhares de povos originários do continente americano. Porém, é especialmente relevante destacar de que modo este conceito que foi historicamente utilizado para justificar violências e que carregava uma grande carga depreciativa (especialmente no Brasil, diante do mito do indígena indolente/preguiçoso), veio a se tornar um símbolo de identidade e parte importante no processo de luta e articulação política dos povos originários.

Após o processo de ressignificação pelo qual passou as relações inter-étnicas na América Latina, a terminologia 'índio' na segunda metade do século XX, também passou por uma redefinição. Após esses debates foi possível pluralizar a terminologia 'índio/indígena' por 'sociedades tradicionais' e 'populações nativas' para designar as comunidades até então denominadas por uma única nomenclatura: indígenas. Esse novo cenário tem resultado, em um processo denominado etnogênese, a partir do qual os povos indígenas reivindicam suas identidades étnicas e requerem o reconhecimento tanto de suas etnicidades, quanto de suas territorialidades e pertencimento jurídico.

Segundo Clímaco (2014, p. 13-14):

La colonialidad del poder condiciona la entera existencia social de las gentes de todo el mundo, ya que la racialización delimita de modo decisivo la ubicación de cada persona y cada pueblo en las relaciones de poder globales. Pero es en América, en América Latina sobre todo, que su cristalización se hace más evidente y traumática, puesto que aquí la diferenciación racial entre "indios", "negros", "blancos", y "mestizos" ocurre al interior de cada

\footnotetext{
${ }^{10}$ Para esse tema também pode colaborar o artigo de Enrique Del Percio - La fraternidade como principio relacional jurídico y político. Buenos Aires: UBA, 2014.

${ }^{11}$ Para o tema realizaram-se leituras de Hall, Richard Hoggart e Raymond Williams. Também colaboram as obras de Drew, Julie. "Cultural Composition: Stuart Hall on Ethnicity and the Discursive Turn". Gary A. Olson and Lynn Worsham (eds.). Race, Rhetoric and the Postcolonial. Albany, NY: State University of New York Press, 1999 e Hall, Stuart. Da diáspora: identidades e mediações culturais. (1 a impressão revista) Belo Horizonte/Brasília: Editora UFMG/Unesco, 2006.
} 
país. Encarnamos la paradoja de ser Estados-nación modernos e independientes y, almismo tiempo, sociedades coloniales, en donde toda reivindicación de democratización ha sido violentamente resistida por las élites "blancas".

O processo de recuperação e restauração desse ideário histórico e plural deve ocorrer de tal forma que o discurso político se sinta impedido de vir desacompanhado das necessárias transformações identitárias (enquanto reconstrução das identidades dos povos e indivíduos Latino-Americanos) e práticas (priorizando as carências materiais e imateriais básicas, também chamado mínimo ético possível). Como observa Joaquín Herrera Flores (2009, p. 20), a reflexão acerca da realidade avançou na medida em que de seu espaço de pura abstração e mera formalidade, onde se queria que se aceitasse passivamente a ideologia do se estamos ante procedimentos epistemológicos e jurídicos justos, os resultados serão necessariamente justos.

Da mesma forma, os nativos lutam incessantemente para conservar suas tecnologias e a alteridade que estas representam contra o processo de industrialização capitalista e seus processos de estruturação e reestruturação, garantindo assim um elemento de interioridade e autonomia (MOREIRA, 2001. P. 16).

Esses e outros temas também serão marcados pela pesquisa científica na América Latina, tendo como grupo humano de estudo as comunidades nativas. Antropólogos, geógrafos, historiadores, juristas e sociólogos se debruçaram sobre pesquisas com os mais variados métodos de pesquisa. ${ }^{12}$ Entretanto, sinaliza-se que:

La revuelta intelectual contra esa perspectiva y contra ese modo eurocéntrico de producir conocimiento nunca estuvo exactamente ausente, en particular en América Latina. Pero no levanta vuelo realmente sino después de la Segunda Guerra Mundial, comenzando, por supuesto, en las áreas dominadas y dependientes del mundo capitalista. Cuando se trata del poder, es siempre desde los márgenes desde donde suele ser más visto, y más temprano, porque entra en cuestión la totalidad del campo de relaciones y de sentidos que constituye tal poder. Desde América Latina, sin duda la más influyente de las tentativas de mostrar de nuevo la mundialidad del capitalismo fue la propuesta de Raúl Prebisch ${ }^{13}$ y sus asociados, para pensar el capitalismo como un sistema mundial diferenciado en "centros" y "periferias". Tal visión fue retomada y reelaborada en la obra de Immanuel Wallerstein ${ }^{14}$, cuya propuesta teórica del "sistema-mundo moderno", desde una perspectiva donde confluyen la visión marxiana del capitalismo como un sistema mundial y la braudeliana sobre la larga duración

\footnotetext{
${ }^{12}$ Vale assinalar que pesquisadores da questão indígena da América Latina, como STAVENHAGEN, ALBÓ, ANAYA, YASHAR, afirmam que o intento dos movimentos ameríndios é diferente dos problemas étnicos dos países europeus e do Oriente Médio que tem na autodeterminação um elemento preambular para a independência. Os povos indígenas, em geral, pleiteiam conquistar e exercer, no âmbito interno dos Estados, a autodeterminação sem que isso caracterize necessariamente um processo de secessão. Trata-se, portanto, da luta por uma autonomia interna e não externa, em geral praticada, sob a forma de autogoverno local e/ou regional.

${ }^{13}$ As principais obras escritas por Raúl Prebisch são: Introducción a Keynes, 1947;El desarrollo económico de la América Latina y algunos de sus principales problemas,1949;Crecimiento, desequilibrio y disparidades: interpretación del proceso de desarrollo económico, 1950 (considerado por Albert Hirschman como o "Manifesto Latino-Americano");Problemas teóricos y prácticos del crecimiento económico,1951;La cooperación internacionaol en la política de desarrollo latinoamericana,1954;Hacia una dinámica del desarrollo latinoamericano,1963;Nueva política comercial para el desarrollo, 1964;Hacia una estrategia global del desarrollo, 1968;Transformação e desenvolvimento: a grande tarefa da América Latina,1970;Capitalismo periférico: crisis y transformación,1981;Cinco etapas de mi pensamiento sobre el desarrollo,1983;Raúl Prebisch (1901-1986) a construção da América Latina e do Terceiro Mundo (em língua portuguesa) Editado pela Contraponto Editora. Título original The life and times of Raúl Prebisch 1901-1986.

${ }^{14}$ A sua obra fundamental é O sistema mundial moderno (1990), publicada originalmente em três volumes em 1974,1980 e 1989. No Brasil, seus artigos são publicados na revista Fórum e na revista virtual Outras Palavras.
} 
histórica, há reabierto y renovado, de modo decisivo, el debate sobre la reconstitución de una perspectiva global en la investigación científico-social del último cuarto del siglo XX. (QUIJANO, 2014, p. 285)

A problemática aqui estudada decorre do fato da diversidade - posta enquanto desafio da educação contemporânea - identificar a tensão existente entre a pluralidade étnico-cultural e a política de justiça universal. O reconhecimento e a valorização das identidades culturais, ${ }^{15}$ pelo desenvolvimento do multiculturalismo, permite que algumas categorias de indivíduos saiam de inicial isolamento para encontrar atenção e foco na análise multicultural ou pluricultural, assentado no direito à cultura ${ }^{16}$ e a autodeterminação.

Ademais, é o multiculturalismo que consente diferentes experiências derivadas do saber local, que devem ser dispostas e consideradas na construção dos currículos, sem perder de vista a dimensão universal da educação. Assim, as práticas curriculares devem ser baseadas no reconhecimento e na valorização da diversidade cultural.

É neste diapasão que surge o questionamento sobre as práticas pedagógicas ortodoxas e os discursos curriculares homogeneizantes ou etnocêntricos. Assim, esse ensaio ultrapassa o plano exclusivamente teórico para identificar, na produção acadêmica em nível de Pós-Graduação stricto sensu, a temática, mas sim indicar uma nova postura e realidade da produção científica da área jurídica.

\section{APONTAMENTOS SOBRE A PESQUISA DE PÓS-GRADUAÇÃO NO BRASIL}

Os primeiros passos da pós-graduação no Brasil foram dados no início da década de 1930, na proposta do Estatuto das Universidades Brasileiras, onde Francisco Campos ${ }^{17}$ propunha a implantação de uma pósgraduação nos moldes europeus. Tal modelo foi implementado tanto no curso de Direito da Universidade do Rio de Janeiro quanto na Faculdade Nacional de Filosofia e na Universidade de São Paulo. ${ }^{18}$

A década de 1940 marca o uso pela primeira vez do termo "pós-graduação” no Artigo 71 do Estatuto da Universidade do Brasil. Na década de 1950 começaram a ser firmados acordos entre Estados Unidos e Brasil que

\footnotetext{
${ }^{15}$ Segundo Zaffaroni, hay un ser humano latinoamericano que se va abriendo paso en la historia en permanente resistencia al colonialismo, que le niega o retacea su dignidad de persona, en un territorio en que muchos millones de seres humanos interactúan y sincretizan sus cosmovisiones, que son expresión de todas las culturas sometidas y marginadas por el colonialismo en todo el planeta Tierra.

${ }^{16}$ Neste trabalho, o direito à cultura é tomado no sentido de proteção às mais variadas manifestações de grupos étnicos, raciais ou religiosos, abrangendo o direito a viver de acordo com suas tradições e costumes, o direito ao reconhecimento de sua singularidade cultural, a garantia contra a discriminação e a assimilação forçada, o direito à promoção de suas expressões culturais, o direito à autonomia e à autodeterminação, entre outros.

${ }^{17}$ Francisco Campos fora catedrático de Filosofia do Direito na Faculdade de Direito da hoje UFMG - a Casa de Afonso Pena -, e na condição de primeiro Ministro de Educação e da Saúde do Brasil (no cenário da Revolução de 1930 e do ingresso do país no Estado Social), acabou estimulando sua Casa de origem a inaugurar a experiência brasileira de Pós-Graduação. (UFMG, Relatório Técnico, 2015)

${ }^{18} \mathrm{Na}$ virada de 1931 para 1932, a então Universidade de Minas Gerais abriria o curso de doutorado em Direito, em três seções (Direito Público, Direito Privado e Direito Penal), unidas por uma disciplina comum a ambas: a Filosofia do Direito. Nada obstante o pioneirismo da implantação do curso, dadas as circunstâncias acadêmicas da época, em que havia sucessivos concursos de cátedra e de livre-docência, a primeira tese somente viria a ser defendida em 1953, por Walter Bruno de Carvalho, na seção de Direito Público e intitulada 'A posição filosófico-jurídica de Stammler'.
} 
implicavam uma série de convênios entre escolas e universidades norte-americanas e brasileiras por meio do intercâmbio de estudantes, pesquisadores e professores. (SANTOS, 2003.p. 628)

Nesse contexto, é possível apontar que as duas tendências que marcaram a pós-graduação brasileira foram à europeia, (principalmente na USP) e a norte-americana (ITA, Universidade Federal de Viçosa e Universidade Federal do Rio de Janeiro), sendo esta última a que mais deixou marcas. A modernização do Brasil nos anos de 1960 deu-se dentro de um contexto de integração entre países periféricos e países centrais. Essa integração implicava a expansão de mercados consumidores nos países periféricos e o fomento dos centros produtores de Ciência \& Tecnologia (países centrais). O objetivo das nações 'mais desenvolvidas' era o aumento de mercados consumidores e o desestímulo à concorrência científica ou tecnológica. ${ }^{19}$

Foi neste contexto de dependência em relação às nações centrais que se deu a instalação da pósgraduação no Brasil. Uma sociedade dependente vincula-se a outra, supostamente mais organizada e desenvolvida, para estabelecer uma relação de "parceria subordinada". Tal dependência, contudo, é extremamente nociva, especialmente para a pesquisa, uma vez que a compra de know-howestrangeiro se torna um mau negócio por desestimular as iniciativas de desenvolvimento tecnológico do país importador, limitando a formação de cientistas e pesquisadores. Nesse contexto, o valor do cientista depende do impacto internacional que seu trabalho tem e da consonância do tema de sua pesquisa com os interesses dos países desenvolvidos. A interferência da United States Agency for International Development (USAID) nos rumos da educação brasileira na década de 1960 deve ser entendida sob esta ótica (ROMANELLI, 1993, p. 196; WEREBE, 1994, p. 173).

Através do parecer 977 do Conselho Federal de Educação, inicia a fase que estabelecia a pós-graduação conforme o modelo norte-americano no Brasil. A pós-graduação stricto sensu dar-se-ia em dois níveis independentes e sem relação de pré-requisitos entre o primeiro e o segundo (mestrado e doutorado). A primeira parte dos cursos seria destinada a aulas e a segunda à confecção do trabalho científico de conclusão (dissertação ou tese). Os currículos seriam compostos conforme o modelo norte-americano, que compreendia o major (área de concentração) e o minor (matérias conexas). ${ }^{20}$

As décadas que seguiram até a atualidade é mantido esse padrão mesmo que apresente uma série de contradições pedagógicas. Uma severa crítica é feita ao modelo brasileiro de pós-graduação devido sua dependência cultural e metodológica. Segundo Ernst Hamburger, a regulamentação da pós-graduação no Brasil foi copiada até nos mínimos detalhes da norte-americana" (HAMBURGER, 1980, p. 84).

Segundo Varella (2012. p. 131), nos últimos dez anos, o número total de cursos subiu de pouco mais de 20 para cerca de 80 . O número de Doutorados em Direito avançou de pouco mais de cinco cursos para 31. Com

\footnotetext{
${ }^{19} \mathrm{Em}$ 1965, com o Parecer 977 do Conselho Federal de Educação, ocorre a implantação formal dos cursos de pós-graduação no Brasil. Segundo Newton Sucupira, o modelo de pós-graduação a ser implantado era adequado à nova concepção de universidade, oriundo dos países mais desenvolvidos.
} 
o avanço dos cursos com conceito 4 na última avaliação trienal, em 2013, existe um potencial de aumento para quase 50 cursos de doutorado em Direito.

Por outro lado, há poucos pesquisadores-juristas brasileiros reconhecidos no exterior. O país se ressente de uma maior participação nas redes de pesquisa em âmbito internacional, ou seja, as mais importantes. O Brasil é, sem dúvida, um país periférico na produção do conhecimento jurídico mundial. O desafio é como transformar esses variados cursos localizados nos mais diversos Estados do País em uma das melhores ou mais influentes produções de Pós-Graduação em Direito.

Nesse aspecto, urgem críticas sobre as áreas temáticas e objetos de pesquisa eleitos na elaboração de análises científicas no campo do Direito. Muitas categorias sociais, mesmo sendo a maioria na composição da sociedade foram relegadas em nome dos ditos grandes temas. Em se tratando do Direito - há uma forte tendência enquanto procedimento metodológico a reprodução de pesquisas bibliográficas com uso de técnica jurídica - em contraposição a Ciência Jurídica. ${ }^{21}$

É nesse aspecto que esse ensaio busca identificar as produções que abarcaram como temática e objeto de pesquisa as comunidades nativas, povos tradicionais ou comunidades indígenas em Universidades da Argentina ${ }^{22}$, Brasil e Peru.

\section{Comunidades nativas no Brasil e a produção acadêmica}

A título de amostragem utilizaremos para essa análise a Universidade Federal de Santa Catarina - que se localiza no Sul do Brasil. A opção pela instituição se dá especialmente pela facilidade as informações, o acesso as fontes e seu destaque acadêmico-científico. ${ }^{23}$

$\mathrm{Na}$ senda histórico-evolutiva, o ensino jurídico ${ }^{24}$ e a pesquisa em nível de Pós-Graduação no Brasil passam por distintas fases teóricas, fundamentadas, basicamente, pela teoria política. A primeira resta evidenciada no modelo de Estado Liberal, a segunda no Estado Social e, por fim, no Estado Neoliberal.

Por muito tempo foi possível observar na história do ensino de Direito no Brasil a desvinculação entre

\footnotetext{
${ }^{20}$ BRASIL. Conselho Federal de Educação. Parecer n 977/65. Definição dos cursos de pós-graduação. Brasília, DF, 1965.

${ }^{21}$ Para essa questão de análise vide Sampaio Ferraz Jr., Tércio. A ciência do direito. São Paulo: Atlas, 1977.

${ }^{22}$ Foram analisadas no banco de dados digital da UBA os trabalhos disponibilizados no período de 1950 - 2015; 389 trabalhos da UFSC e um total de 312 trabalhos incluindo a Universidade Nacional Mayor de San Marcos, a Pontifícia Universidade Católica de Lima e Universidad Nacional Federico Villarreal (UNFV) / Peru.

${ }^{23}$ Acresce-se também a escolha da UFSC nesse trabalho devido a seu pioneirismo temporal já que o Curso Superior em Direito que foi criado em 1932.

${ }^{24}$ Para Bastos (2000, p. 61), os currículos jurídicos no Brasil, assim como os modelos de organização e estruturação dos cursos jurídicos, refletem as propostas de um estado que se pensa dogmaticamente e oferece sugestões exclusivamente dogmáticas para o encaminhamento dos conflitos e contradições sociais, desprezando a experiência acumulada dos tribunais, a jurisprudência, como parâmetro de elaboração legal, o que enfraquece não só o Poder Judiciário, como centro de experimentação e fomento de decisões legais, assim como a profissão de advogado enquanto agente legal de intermediação entre as contradições sociais, ou mesmo entre estas e o estado.
} 
educação e realidade social. As alterações que eram identificadas nos cursos de Direito baseavam-se nas contrafações de regimes políticos, sendo importante mencionar a exigência de maior profissionalização dos egressos e a influência do positivismo na concepção de Direito. Em 1931, com a Reforma Francisco Campos, procurou-se dar aos cursos de Direito um caráter profissionalizante, sendo que foram desdobrados o Bacharelado e o Doutorado, cabendo ao primeiro a formação de operadores técnicos e ao segundo a preparação dos futuros professores e pesquisadores. "Essa reforma, no entanto, não obteve, na época, o êxito esperado, continuando os cursos de bacharelado no mesmo nível existente anteriormente e não tendo os de doutorado atingido os objetivos almejados". (RODRIGUES, 2002, p. 20).

O curso de graduação em Direito ${ }^{25}$ da Universidade Federal de Santa Catarina é a continuidade da Faculdade de Direito de Santa Catarina, fundada em Florianópolis, no dia 11 de fevereiro de 1932 e incorporada à UFSC quando de sua criação, em 18 de dezembro de 1960. (UFSC, 2004).

O curso experienciou, no decorrer dos anos, várias mudanças em sua estrutura jurídica: começou como sociedade civil; passou posteriormente a integrar o sistema educacional do Estado, em 1935, sendo então pessoa jurídica de direito público; voltou à condição de pessoa jurídica de direito privado em 1938, tendo em vista as disposições do artigo 159 da Constituição de 10 de novembro de 1937, que proibiam a acumulação de funções e cargos públicos, situação que atingia a maioria de seus professores; em 1956 foi federalizada, sendo em 1960 incorporada pela UFSC. (UFSC, 2004).

Nos documentos pedagógicos do curso, é recorrente a UFSC indicar ter desenvolvido um projeto pedagógico com alusão a base humanista, justificando aliar à formação teórica, dogmática e prática para uma formação voltada ao desenvolvimento de uma cidadania e participação social. Destaca-se também que o curso de graduação em Direito da Universidade Federal de Santa Catarina foi um dos pioneiros a implantar o trabalho de conclusão e as atividades curriculares complementares, já no ano de 1992.

Já o Programa de Pós-Graduação em Direito da UFSC, criado em 1973 dentro de um espírito de inovação dos programas stricto sensu no Brasil, se consolidou como um dos mais conceituados do país, obtendo, no triênio de 2001-2003, no triênio 2004-2006 e no triênio de 2007-2010, a nota 6 na avaliação CAPES, resultado da ampla reformulação e devida implementação de novas grades curriculares no decorrer do período. Em seu processo evolutivo, o Programa de Mestrado estabeleceu linhas de Pesquisa estruturadas nas seguintes áreas de concentração: Teoria, Filosofia e História do Direito; Direito, Estado e Sociedade; Direito e Relações Internacionais. (UFSC, 2004)

Segundo o Projeto Político Pedagógico do Curso (2010), no Doutorado, para atender as

\footnotetext{
${ }^{25}$ A graduação em Direito, possui 160 vagas anuais, divididas em quatro turmas de 40 alunos cada, sendo duas noturnas e duas diurnas, com entradas em março e agosto. Os conteúdos e atividades mínimas desenvolvidas pelos acadêmicos devem somar 3.000
} vol.10, no. 01, Rio de Janeiro, 2017.pp. 149-177 
transformações políticas verificadas na sociedade moderna, foi criada a área de concentração Direito, Política e Sociedade. O programa acadêmico surgiu com uma inovação dentre os, até então, implementado no Brasil; atento à crescente importância da Filosofia e do Direito Crítico e às transformações internacionais. ${ }^{26} \mathrm{Com}$ um viés epistemológico eminentemente crítico e interdisciplinar, pretendeu estimular a formação de profissionais/acadêmicos dotados de elevados padrões científicos, sem, contudo, desconsiderar a relevância dos valores éticos e de responsabilidade social. (UFSC, 2010)

A pesquisa realizada no banco de dados de dissertações e teses da Universidade Federal de Santa Catarina apontou entre os anos de 1990 - 2015 um total de 16 trabalhos apresentados e defendidos tendo por objeto central a temática proposta nesse estudo. Nesse aspecto apresenta-se na tabela abaixo a data/ano de defesa, o nome do pesquisador, o título final do trabalho e a comissão avaliadora ou seu presidente/orientador.

Tabela 1 - Dissertações e Teses aprovadas na UFSC - Programa de Pós-Graduação em Direito (1990-2015)

\begin{tabular}{|c|c|c|c|}
\hline \multicolumn{4}{|c|}{ Temática indígenas e comunidades tradicionais } \\
\hline Data & Pesquisador & Título & Comissão Julgadora/banca \\
\hline 03/1992 & $\begin{array}{c}\text { Álvaro Reinaldo de } \\
\text { Souza }\end{array}$ & $\begin{array}{c}\text { Minorias étnicas: o índio perante o Direito } \\
\text { brasileiro } \\
{ }^{*} \text { Dissertação }\end{array}$ & $\begin{array}{l}\text { Dr. Osni de Medeiros Regis } \\
\text { (Presidente) } \\
\text { Dr. Dalmo de Abreu Dalari } \\
\text { (Membro) } \\
\text { Dr. Sílvio Coelho dos Santos } \\
\text { (Membro) }\end{array}$ \\
\hline 08/1994 & Manoel Bessa Filho & $\begin{array}{c}\text { Um direito de autodeterminação para as } \\
\text { sociedades tribais } \\
{ }^{*} \text { Dissertação }\end{array}$ & $\begin{array}{c}\text { Dr. Osni de Medeijlros Rêgis } \\
\text { - UFSC } \\
\text { (Presidente) } \\
\text { Dr. Cêsar Luiz Pasold } \\
\text { (Membro) } \\
\text { Dra. Neusa Maria Bloemer } \\
\text { (Membro) }\end{array}$ \\
\hline 04/08/98 & Thais Luzia Colaço & $\begin{array}{c}\text { O direito guarani pré-colonial e as missões } \\
\text { jesuíticas: a questão da incapacidade religiosa } \\
\text { e da tutela religiosa } \\
{ }^{*} \text { Tese }\end{array}$ & $\begin{array}{c}\text { Dr. Antonio Carlos Wolkmer } \\
\text {-UFSC } \\
\text { (Presidente) } \\
\text { Dr. Edson Luiz Fachin } \\
\text { (Membro) }\end{array}$ \\
\hline
\end{tabular}

h/a e 300 h/a de Estágio de Prática Jurídica, com o total de 3.300 h/a. Já a duração plena é de 3.292 h/a de disciplinas, 288 h/a de atividades complementares e $380 \mathrm{~h} / \mathrm{a}$ de Estágio de Prática Jurídica, perfazendo o total de $3.960 \mathrm{~h} /$ a. (UFSC, 2004).

${ }^{26}$ Esse ideário conjuga com as perspectivas críticas surgidas na América Latina e por consequência no Brasil, momento a qual abriram-se novas possibilidades para mudanças no campo do ensino do Direito e da pesquisa. Essa perspectiva, podemos dizer que é um suporte adequado e equipado com um projeto alternativo e mesmo a alternatividade clássica: jacobinismo (liberal), o marxismo crítico e democracia norte-americana, que rompe muitos desses postulados políticos; para construir um projeto voltado para a comunidade, os territórios, a autonomia e os processos baseados na relação dos diferentes." (MEJÍA JIMÉNEZ, 2012) vol.10, n'. 01, Rio de Janeiro, 2017.pp. 149-177 158 


\begin{tabular}{|c|c|c|c|}
\hline & & & $\begin{array}{c}\text { Dra. Paula Caleffi Giorgis } \\
\text { (Membro) } \\
\text { Dr. Arthur Cesar Isaia } \\
\text { (Membro) } \\
\text { Dra. Josiane Rose Petry } \\
\text { Veronese } \\
\text { (Membro) }\end{array}$ \\
\hline $03 / 05 / 02$ & $\begin{array}{c}\text { Álvaro Reinaldo de } \\
\text { Souza }\end{array}$ & $\begin{array}{l}\text { Os povos indígenas: minorias étnicas e a } \\
\text { eficácia dos Direitos Constitucionais no } \\
\text { Brasil } \\
{ }^{*} \text { Tese }\end{array}$ & $\begin{array}{c}\text { Dr. Edmundo Lima de } \\
\text { Arruda Jr., (Presidente) } \\
\text { Dr. Carlos Frederico Marés } \\
\text { de Souzajilho (Membro) } \\
\text { Dr. Silvio Coelho dos Santos } \\
\text { (Membro) } \\
\text { Dr. Clemerson Melin Cléve } \\
\text { (Membro) } \\
\text { Dr. José Alcebíades de } \\
\text { Oliveira Jr. (Membro) }\end{array}$ \\
\hline $19 / 05 / 03$ & $\begin{array}{l}\text { Antonio Armando } \\
\text { Ulian do Lago } \\
\text { Albuquerque }\end{array}$ & $\begin{array}{c}\text { Multiculturalismo e o direito à } \\
\text { autodeterminação dos povos indígenas } \\
\text { *Dissertação }\end{array}$ & $\begin{array}{c}\text { Dra. Thaís Luzia Colaço - } \\
\text { UFSC } \\
\text { (Presidente) } \\
\text { Dr. Antonio Carlos Wolkmer } \\
\text {-UFSC } \\
\text { (Membro) } \\
\text { Dr. Alvaro Reinaldo de Souza } \\
\text {-UFSC } \\
\text { Membro }\end{array}$ \\
\hline 2005 & $\begin{array}{l}\text { Isaias Montanari } \\
\text { Júnior }\end{array}$ & $\begin{array}{l}\text { Demarcação de terras indígenas na faixa de } \\
\text { fronteira sob o enfoque da defesa nacional } \\
{ }^{*} \text { Dissertação }\end{array}$ & $\begin{array}{l}\text { Dr. Sergio Urquhart } \\
\text { Cademartori } \\
\text { Membros da Banca não } \\
\text { disponível no Arquivo } \\
\text { consultado }\end{array}$ \\
\hline $27 / 03 / 08$ & $\begin{array}{c}\text { Adriana Biller } \\
\text { Aparício }\end{array}$ & $\begin{array}{c}\text { Direitos territoriais indígenas: diálogo entre o } \\
\text { direito e a antropologia - o caso da terra } \\
\text { Guarani Morro dos Cavalos }\end{array}$ & $\begin{array}{c}\text { Dr. Thais Luzia Colaço - } \\
\text { UFSC (Presidente) } \\
\text { Dr.Antonio Carlos de Souza } \\
\text { Lima - UFCS (Membro) } \\
\text { Dra. Maria Dorothea Post } \\
\text { Darella (Membro) } \\
\text { Dr. Antonio Carlos Wolkmer } \\
\text { - UFSC(Membro) }\end{array}$ \\
\hline 05/07/10 & $\begin{array}{c}\text { João Francisco } \\
\text { Kleba }\end{array}$ & $\begin{array}{l}\text { O Direito entre os Kaingang no Oeste de } \\
\text { Santa Catarina: um olhar a partir da } \\
\text { Antropologia Jurídica } \\
{ }^{*} \text { Dissertação }\end{array}$ & $\begin{array}{c}\text { Dra. Thaís Luzia Colaço - } \\
\text { UFSC (Presidente) } \\
\text { Dr. Ricardo Cid Fernandes - } \\
\text { UFPR (Membro externo) } \\
\text { Dra. Danielle Annoni - } \\
\text { UFSC (Membro) } \\
\text { Dr. Rogério Silva Portanova } \\
\text { - UFSC (Suplente) }\end{array}$ \\
\hline $05 / 07 / 10$ & Juliana de Paula & Tecendo o Direito: a organização política & Dra. Thaís Luzia Colaço - \\
\hline
\end{tabular}




\begin{tabular}{|c|c|c|c|}
\hline & Batista & $\begin{array}{c}\text { dos Xokleng - La Klãnõ e a construção de } \\
\text { sistemas jurídicos próprios - uma } \\
\text { contribuição para a antropologia jurídica } \\
{ }^{*} \text { Dissertação }\end{array}$ & $\begin{array}{c}\text { UFSC (Presidente) } \\
\text { Dra. Raquel Fabiana Lopes } \\
\text { Sparemberger - UCS } \\
\text { (Membro externo) } \\
\text { Dr. Rogério Silva Portanova } \\
\text { - UFSC (Membro) } \\
\text { Dra. Danielle Annoni - } \\
\text { UFSC (Suplente) }\end{array}$ \\
\hline $20 / 10 / 11$ & $\begin{array}{l}\text { Susana Andréa } \\
\text { Inácio Belfort }\end{array}$ & $\begin{array}{c}\text { Conhecimento tradicional indígena: } \\
\text { revitalização das expressões culturais do povo } \\
\text { Kaingang da Terra Indígena Serrinha/RS e } \\
\text { Aldeia Condá/SC } \\
\text { *Dissertação }\end{array}$ & $\begin{array}{l}\text { Dra. Thais Luzia Colaço - } \\
\text { UFSC (Presidente) } \\
\text { Dr. Antonio Carlos Wolkmer } \\
\text { - UFSC (Membro) } \\
\text { Dra. Raquel Fabiana Lopes } \\
\text { Sparemberger - UFPel } \\
\text { (Membro externo) }\end{array}$ \\
\hline $27 / 07 / 11$ & Mayra Silveira & $\begin{array}{l}\text { O infanticídio indígena: uma análise à luz da } \\
\text { Doutrina da Proteção Integral } \\
{ }^{*} \text { Dissertação }\end{array}$ & $\begin{array}{c}\text { Dra. Josiane Rose Petry } \\
\text { Veronese - UFSC } \\
\text { (Presidente) } \\
\text { Dra. Thais Luzia Colaço - } \\
\text { UFSC (Membro) } \\
\text { Dra. Heloísa Maria José de } \\
\text { Oliveira - } \\
\text { CESUSC (Membro externo) } \\
\text { Dr. Luís Carlos Cancellier de } \\
\text { Olivo - UFSC (Suplente) }\end{array}$ \\
\hline $01 / 12 / 12$ & $\begin{array}{l}\text { Eloise da Silveira } \\
\text { Petter Damázio }\end{array}$ & $\begin{array}{l}\text { Colonialidade e decolonialidade da } \\
\text { (anthropos) logia } \\
\text { jurídica: da universalidade a pluriversalidade } \\
\text { epistêmica } \\
\text { *Dissertação }\end{array}$ & $\begin{array}{l}\text { Dra. Thaís Luzia Colaço- } \\
\text { UFSC (Presidente) } \\
\text { Dra. Raquel Fabiana Lopes } \\
\text { Sparemberger - UCS } \\
\text { (Membro externo) } \\
\text { Dr. Antonio Carlos Wolkmer } \\
\text { - UFSC (Membro) } \\
\text { Dr. Paulo Ávila Fagundes } \\
\text { (Membro) } \\
\text { Dr. Antônio José Guimarães } \\
\text { Brito (Membro) }\end{array}$ \\
\hline 2015 & $\begin{array}{l}\text { Isabella Cristina } \\
\text { Lunelli }\end{array}$ & $\begin{array}{c}\text { Pluralismo Jurídico no Brasil: diálogos entre } \\
\text { o direito estatal e o direito indígena } \\
{ }^{*} \text { Dissertação }\end{array}$ & $\begin{array}{c}\text { Dr. Antonio Carlos Wolkmer } \\
\text { - UFSC } \\
\text { (Presidente) } \\
\text { Dr. Sidney Francisco Reis } \\
\text { dos Santos - FESSC } \\
\text { (Membro) } \\
\text { Dra. Ivone Fernandes } \\
\text { Morcilo Lixa - FURB } \\
\text { (Membro) } \\
\text { Dra. Lidia Patricia Castillo } \\
\text { Amaya - UFSC (Membro) }\end{array}$ \\
\hline
\end{tabular}




\begin{tabular}{|c|c|c|c|}
\hline $26 / 02 / 15$ & $\begin{array}{l}\text { Efendy Emiliano } \\
\text { Maldonado Bravo }\end{array}$ & $\begin{array}{l}\text { Histórias da Insurgência Indígena e } \\
\text { Campesina: o processo constituinte } \\
\text { equatoriano desde o pensamento crítico } \\
\text { latino-americano }\end{array}$ & $\begin{array}{c}\text { Dr. Antonio Carlos } \\
\text { Wolkmer, Dr. (Presidente) } \\
\text { Universidade Federal de } \\
\text { Santa Catarina } \\
\text { Dr. Carlos Frederico Marés, } \\
\text { Dr. } \\
\text { Pontifícia Universidade } \\
\text { Católica do Paraná } \\
\text { (Membro externo) } \\
\text { Dr. José Geraldo de Sousa } \\
\text { Júnior, Dr. } \\
\text { Universidade de Brasília } \\
\text { (Membro externo) } \\
\text { Dr. Alejandro Rosillo, Dr. } \\
\text { Universidad Autónoma de } \\
\text { San Luís Potosí-MX } \\
\text { (Membro externo) }\end{array}$ \\
\hline 2015 & $\begin{array}{c}\text { Flávia do Amaral } \\
\text { Vieira }\end{array}$ & $\begin{array}{l}\text { Direitos Humanos e desenvolvimento na } \\
\text { Amazônia: Belo Monte na Comissão } \\
\text { Interamericana de Direitos Humanos } \\
{ }^{*} \text { Dissertação }\end{array}$ & $\begin{array}{c}\text { Dr. }{ }^{a} \text { Leticia Albuquerque - } \\
\text { UFSC (Presidente) } \\
\text { Membros da Banca não } \\
\text { disponível no Arquivo } \\
\text { consultado }\end{array}$ \\
\hline 2016 & $\begin{array}{c}\text { Fernando da Silva } \\
\text { Mattos }\end{array}$ & $\begin{array}{l}\text { A proteção dos direitos indígenas pelo } \\
\text { Ministério Público: uma análise na } \\
\text { perspectiva da teoria crítica dos direitos } \\
\text { humanos. } 2016 . \\
{ }^{*} \text { Dissertação }\end{array}$ & $\begin{array}{c}\text { Dra. Thais Luzia Colaço } \\
\text { (Presidente) } \\
\text { Dr. Antonio Carlos Wolkmer } \\
\text { - UFSC (Membro) } \\
\text { Dr. Roberto Verdum - } \\
\text { UFRGS (Membro) } \\
\text { Dr.J. M. Barbosa (Membro } \\
\text { externo) }\end{array}$ \\
\hline
\end{tabular}

Tabela elaborada pelos autores. Fonte: Acervo de Teses - Universidade Federal de Santa Catarina - Programa de Pós-Graduação em Direito, 2016.

Acresce-se a esse espaço de formação e pesquisa - UFSC três grupos de pesquisa registrados na base do $\mathrm{CNPq}^{27}$ e certificados pela Pró-Reitoria de Pesquisa e Pós-graduação da UFSC, que contam com a participação, tanto de discentes da graduação, como dos mestrandos e doutorandos que se dedicam também a temática comunidades tradicionais. São eles: História da Cultura Jurídica coordenado por Arno Dal Ri Júnior e Antropologia Jurídica-GPAJU - UFSC e a Experiência Jurídica na América Latina - Sob o olhar antropológico -

\footnotetext{
${ }^{27}$ Conselho Nacional de Pesquisa, que atualmente é chamado de Conselho Nacional de Desenvolvimento Científico e Tecnológico. É um órgão público que tem o objetivo de incentivar a pesquisa no Brasil. O CNPQ foi fundado em 1951, sendo reconhecido no mundo todo, em especial nos países em desenvolvimento. Inicialmente o CNPQ tinha o objetivo de dominar o ciclo atômico no país, e criar estratégias. Porém, depois expandiram-se as funções e o CNPQ ficou responsável também por financiar pesquisas científicas e tecnológicas nas mais diversas áreas de conhecimento. A sede do CNPQ está situada em Brasilia e está ligado ao Ministério da Ciência e Tecnologia. O CNPQ também tem vários outros órgãos federais e parceiros estrangeiros em suas funções. O CNPQ incentiva a pesquisa no Brasil através de bolsas e auxílios, em especial para indivíduos que querem cursar Mestrado e Doutorado, sejam eles no Brasil ou no Exterior.
} 
tendo como líder a pesquisadora Thais Luzia Colaço.

Enquanto Linha de Pesquisa o Programa de Pós-Graduação em Direito da UFSC oferece 06 linhas, sendo duas delas propensas a analisar a temática povos indígenas e comunidades nativas:

1. Nome: Conhecimento Crítico, Historicidade, Subjetividade e Multiculturalismo

2. Área de Concentração: Teoria, Filosofia e História do Direito

3. Nome: Constituição, Cidadania e Direitos Humanos

4. Área de Concentração: Direito, Estado e Sociedade

5. Nome: Direito da Sociedade de Informação e Propriedade Intelectual

6. Área de Concentração: Direito, Estado e Sociedade

7. Nome: Direito, Meio Ambiente e Ecologia Política

8. Área de Concentração: Direito, Estado e Sociedade

9. Nome: Sociedade, Controle Social e Sistema de Justiça

10. Área de Concentração: Direito, Estado e Sociedade

11. Nome: Globalização, Regionalismo e Atores das Relações Internacionais

12. Área de Concentração: Direito e Relações Internacionais (UFSC, PPC, 2014)

\section{COMUNIDADES NATIVAS NA ARGENTINA E A PRODUÇÃO CIENTÍFICA}

A Universidade de Buenos Aires (UBA) foi fundada em 1821 e figura como a mais importante da República Argentina. Atua no rol das Universidades públicas - é nacional (federal) e atende os níveis de ensino em Graduação e Pós-Graduação. Esta, antecede em 39 anos à organização do país (1860). Por isso, ela faz questão de manter seu nome original, sem o adjetivo.

A pesar de las condiciones precarias en las que desarrollaba sus actividades, la Universidad cumplió un papel central en la socialización de las clases dirigentes porteñas durante las décadas centrales del siglo XIX. El creciente número de graduados da testimonio de esta importancia. Entre 1831 y 1837 se graduaron entre 11 y 12 estudiantes en el departamento de jurisprudencia, en 1850 fueron 18 y 17 en 1852. En el de Medicina egresaron un promedio de 11 estudiantes entre 1838 y 1852 . Este papel central en la formación de las élites se acentuó después de 1852 cuando, una vez derrocado el gobierno de Juan Manuel de Rosas, el país entró en una nueva etapa signada por el comienzo de la organización constitucional y la conformación del estado nacional. Los estudios superiores brindaban una serie de habilidades y conocimientos fundamentales para todos aquellos atraídos por la vida política y la administración pública y muchos de sus estudiantes, formados en aquellas épocas de guerras y conflictos, desempeñarían un papel central en la vida pública de la Argentina de la segunda mitad del siglo XIX. Por otra parte, la Universidad recuperó desde entonces las partidas que le habían sido sustraídas y se abocó a reorganizar su estructura. La Facultad de Medicina fue separada de la institución hasta 1874 y por eso sus funciones se concentraron en los Departamentos de Estudios Preparatorios y de Jurisprudencia. En este último, cuya actividad estaba dominada sobre todo por dos cátedras, las de Derecho Canónico y Derecho Civil y de Gentes se agregaron, entre otras, las de Economía Política y 
luego las de Derecho Criminal y Mercantil. Se transformó el plan de estudios, pero la implementación de nuevas asignaturas se pospuso en varias oportunidades ya que no se encontraron profesores en condiciones de asumirlas. Estas dificultades llevaron incluso a la contratación de profesores extranjeros: el italiano Clemente Pinoli se hizo cargo de la cátedra de Economía Política y un destacado jurista colombiano, Florentino González, se hizo cargo de la de Derecho Constitucional y Administrativo en 1868. (UBA, Programa Historia y memoria, 2015)

Durante a década de 1880, a Universidade de Buenos Aires presenciou mudanças substanciais. Em grande medida, elas estavam ligadas à sua nacionalização, que ocorreu apenas no início da década seguinte. A Universidade foi transferida para hasta nacional após a federalização de Buenos Aires e foi acompanhada nesse processo por outras instituições culturais e educacionais, como a Biblioteca Pública da Província. A partir desse momento, também começaram a ser dirigidas a partir das leis estaduais e nacionais uma série de medidas específicas que foram destinados principalmente para garantir o estabelecimento de um sistema de educação secular. Neste contexto, houve a aprovação da lei (jurisdição nacional) 1420 com vistas ao ensino primário gratuito e obrigatório secular. (UBA, Programa Historia y memoria: 200 años de la Uba, 2015)

No início do século XX, a Universidade de Buenos Aires adquire autonomia pedagógica decorrente da reforma universitária instituída por docentes, discentes e egressos (1918). Segundo Buchbinder (2005, p. 4),

En 1916 la Universidad de Buenos Aires contaba con 5400 estudiantes. El crecimiento del número de estudiantes fue acompañado por el surgimiento de las primeras organizaciones gremiales: en 1900 el centro de estudiantes de medicina, en 1903 el de Ingeniería y en 1905 los de derecho y filosofía y letras. En 1908 se fundó la Federación Universitaria de Buenos Aires. El régimen de exámenes era otro de los puntos conflictivos a principios de siglo. Frente a la sucesión de conflictos y protestas de los estudiantes en relación con las cuestiones mencionadas, la conducción de un nuevo rector en 1906, Eufemio Uballes, permitió reformar los estatutos ese mismo año. Los cambios terminaron con el poder de las academias con miembros vitalicios, con los exámenes generales y con los cuestionados nombramientos de profesores.

Entre os anos de 1918 e $1943^{28}$ foram implantadas diversas reformas no sistema de ensino da

Universidade de Buenos Aires. Nesse diapasão,

Con la reforma se inició un lento proceso de renovación del profesorado universitario que permitió el ascenso de sectores de clase media que ejercían libremente su profesión y enseñaban, desplazando a los miembros de destacadas familias de élite que habían monopolizado el ejercicio de la docencia hasta principios de siglo, configurando así los inicios de una carrera académica. Este hecho tenía relación con la necesidad de atender las demandas de un alumnado creciente. En 1906 había 1942 alumnos matriculados en las universidades y diez años después llegaban a 7000, y en 1920 la matrícula alcanzaba 12116 alumnos. (BUCHBINDER, 2005, p. 4-12),

Com a vitória de Perón (1946), as Universidades foram novamente espaço de intervenção

\footnotetext{
${ }^{28}$ O golpe de 1943 que derrubou Castillo levou ao poder um grupo de conservadores e nacionalistas e, em sua maioria católicos. Esse período marcou por uma profunda transformação da educação pública - reforçando o apelo ao ensino tradicional e introduzido o ensino obrigatório da religião nas escolas. Houve também intervenção nas Universidades, momento a qual foram presos muitos estudantes, acompanhada da suspensão das atividades dos centros estudantis, a expulsão de estudantes identificados como de oposição e protestos contínuos. Em julho de 1945 ocorreu uma conferência nacional de reitores de onde se reivindicou pleno respeito à autonomia universitária e o retorno à normalidade institucional.
} 
governamental. Centenas de professores foram perseguidos ou transferidos de setor. Essa ação também incidiu sobre os estudantes. Muitos foram expulsos das Universidades e outros optaram por abandonar as salas de aulas por medo da repressão.

En los años del primer peronismo la universidad pública debió comenzar a enfrentar agudos problemas. En 1947 había 51.447 estudiantes universitarios, 3 por cada mil habitantes, pero en 1955 ya sumaban 140.000, 8 por cada mil habitantes. Este explosivo crecimiento de la matrícula se debía a las mayores posibilidades de acceso a la educación secundaria y superior, posibilitada, entre otras medidas, por la supresión de los aranceles a la educación superior dispuesta en 1950 y del examen de ingreso en 1953, junto a un sistema de becas ya vigente desde los años cuarenta. Este proceso fue acompañado por un altísimo aumento de las tasas de deserción, a razón de cinco graduados cada ochenta ingresantes. La crisis económica de 1949 limitó el presupuesto y suspendió proyectos de reformas edilicias, acentuando el deterioro de la infraestructura de las casas de altos estudios. Estadísticas de la unión de universidades latinoamericanas (México) de 1956 indican que Argentina posé́a la población unuversitaria más numerosa de América Latina, $0.8 \%$ de la población, mientras que la secundaria de $2.48 \%$ solo era superada por Puerto Rico. (BUCHBINDER, 2005, p. 12-15)

Em meados da década de 1950, estima-se que a UBA tinha 71.823 estudantes, sendo metade deles distribuídos entre as faculdades de Ciências Médicas, Direito e Ciências Sociais. Destes apenas 8\% se formaram dentro dos prazos. A composição social também mudou. No final dos 50 estudantes de setores populares que chegaram a 18,4\% em Buenos Aires e 11\%, em La Plata, sendo que as duas universidades concentram 60\% dos estudantes universitários em todo o país. Esse panorama trouxe a pauta o debate da descentralização, o aumento de vagas e as novas formas de ingresso discente. Esse cenário também impulsionou a abertura das instituições de Ensino Superior de cunho privado. (GARCIA, 2014, p. 461-484)

Un año después de la sanción de la ley que permitía su creación las instituciones casas de estudios se unieron en 1962 y fundaron el Consejo de Rectores de las Universidades Privadas. En 1960 se creó la Universidad de Morón y el Instituto tecnológico de Buenos Aires, en 1962 la Universidad argentina de la empresa y en 1964 la de Belgrano. En 1984 las universidades privadas contaban ya con 88.000 estudiantes, 8.200 profesores y habían emitido desde su creación más de 90.000 títulos. Una disposición de mediados de los años 70 las liberó de la supervisión estatal en la emisión de los títulos profesionales privadas contaban ya con 895 estudiantes y 351 docentes. (BUCHBINDER, 2005, p. 13- 5)

O regime ditatorial deixou marcas na formação dos estudantes e formação dos docentes universitários. Nessa senda, no período de transição do período militar ao democrático foi possível identificar diversos problemas surgidos em função dos ordenamentos político-ideológico vivenciados nas duas últimas décadas nas estruturas das Universidades. Houve o ingresso de um significativo número de estudantes, porém com objetivo de inseri-los ao mercado de trabalho, deixando os aspectos de pesquisa e construção do conhecimento em segundo plano. Fato esse que resultou na deterioração das relações acadêmicas. Muitos docentes abdicaram da função de ensinar o que precarizou, por consequência o trabalho dos que permaneceram. Nesse aspecto, registra-se que entre 1984 e 1988 abriram editais de seleção de ingresso para docentes e funcionários em mais ou menos 15.000 vagas. 


\section{Garcias Franco (2014, p. 464-474) acrescenta,}

En 1985 se creó el Sistema Interuniversitario del Cuarto Nivel (SICUN) para desarrollar los estudios de posgrado. La conformación del Consejo Interuniversitario Nacional (CIN), que agrupaba al conjunto de rectores, permitía afrontar de manera orgánica los problemas de diseño y planificación de la política universitaria. A principios de 1989 la hiperinflación licuó los presupuestos de las universidades, lo que generó conflictos gremiales con empleados administrativos y docentes, cuyos salarios ya estaban deteriorados en virtud de que un alto porcentaje del presupuesto (20\%) se destinaba a equipamiento y construcciones necesarios para hacer frente al explosivo crecimiento de la matrícula propiciado por el ingreso irrestricto. En 1984 los alumnos e las universidades superaban el medio millón, en 1985 sumaban 664.000 y en 1986 alcanzaron los 700.000. Durante esos años solo se creó una universidad nacional, la de Formosa en 1988.

Os anos 90 do século XX vieram com novas demandas e desafios, dentre eles: melhoria na remuneração

docente, acessibilidade e permanência dos estudantes, aspectos relacionados ao ensino, pesquisa e extensão. De acordo com Buchbinder (2005, p. 22-24),

[...] paralelamente se organizaron dos mecanismos para incidir en la transformación de la planta docente universitaria y renovar el equipamiento de las universidades: el Programa de Incentivos para los docentes investigadores y el Fondo para el Mejoramiento de la Calidad Universitaria (FOMEC). El Programa de Incentivos, implementado desde finales de 1993 por la SPU tenía como propósito estimular la investigación en las universidades nacionales donde menos de un $15 \%$ de docentes participaba en actividades de investigación científica, además de incrementar las dedicaciones semiexclusivas y exclusivas. Los docentes debían dictar un número determinado de horas, participar de programas de investigación y ser categorizados por una comisión especial. Esto permitió, además de incrementos salariales de hasta un 60\%, introducir la cultura de la evaluación en las universidades. Hacia 1996 veintiséis mil docentes habían sido categorizados y veinte mil recibían los incentivos. En 1997 el 23\% de la planta docente realizaba investigación frente a un 11\% de 1993. El FOMEC era un fondo constituido originalmente con créditos del Banco Mundial y destinado a financiar proyectos de mejoramiento de la calidad de la enseñanza. Se asignaban a las universidades previo concurso y permitía becar a docentes en posgrados, desarrollar bibliotecas, equipar laboratorios, etc. La implementación de estos proyectos, que exigían una contrapartida por parte de las universidades, se iniciaron en 1995 pero fueron dejados sin efecto tras la crisis de 2001.

Segundo Balán \& Fanelli (1993), no final de 2003, as estatísticas oficiais registraram um milhão duzentos e setenta e oito mil alunos no sistema universitário público e $215.000 \mathrm{em}$ privado. O sistema consistia em trinta e oito universidades estaduais, quarenta e uma privada, seis faculdades públicas, doze faculdades privadas, uma universidade internacional e as provinciais. A comunidade universitária da Argentina atingiu 24,1 por mil habitantes, pouco abaixo de países como a Espanha e a França (26,6 por mil) e mais elevados do que no Japão $(21,2$ por mil). Entretanto, sabe-se que o investimento realizado por aluno/ano é muito maior nos países europeus que nos países latino-americanos. No tocante aos cursos, os mais procurados nessa década foram os de Administração, Direito e Medicina. - concentrando mais de 25\% das matrículas. ${ }^{29}$

\footnotetext{
${ }^{29}$ Em geral a política de educação superior na Argentina tende a ignorar a oferta educacional dos institutos terciários (de 3o. grau) não-universitários, que têm um prestígio menor do que a oferta universitária. O sistema de reconhecimento é inteiramente diferente, sendo uma extensão do é vigente para as escolas primárias, secundárias ou especializadas". Jorge Balán and Ana M. García vol.10, nº. 01, Rio de Janeiro, 2017.pp. 149-177 165
} 
Segundo dados do cadastro geral da Universidade (2015), a mesma conta com 78 cursos de graduação e várias opções de pós-graduação - especializações, mestrados, doutorados e pós-doutorados. Cerca de 30\% da investigação científica do país ocorre na instituição. (UBA, Programa Historia y memoria: 200 años de la Uba, 2015)

Já a Faculdade de Direito, atualmente, possui um corpo discente que ultrapassa os 25.000 estudantes e está sediada em uma construção neoclássica que registra reminiscências dóricas junto ao bairro da Recoleta. Assemelha-se às demais universidades públicas do país por ser financeiramente dependente do Estado, sendo autônoma, gratuita e laica. Possui diversos cursos de especialização, ${ }^{30}$ mestrado ${ }^{31}$ e doutorado ${ }^{32}$ e Pós-Doutorado. (UBA, Faculdade de Derecho, 2016)

A pesquisa realizada no banco de dados de trabalhos de pesquisa final - dissertações e teses da Universidade de Buenos Aires apontou entre os anos de 1958 - 2015 um total de 07 teses defendidas tendo por citação a temática analisada conforme tabela abaixo.

Tabela 2 - Teses aprobadas/UBA - Programa de Pós-Graduação em Direito (1959 2015)

\begin{tabular}{|c|c|c|c|}
\hline \multicolumn{2}{|c|}{ Temática indígenas e comunidades tradicionais } \\
\hline no & Autor/a & Título & OBS \\
\hline 958 & $\begin{array}{c}\text { BELGRANO, } \\
\text { Mario Carlos }\end{array}$ & Benjamín Constant y el Constitucionalismo Argentino. & $\begin{array}{c}\text { Tesis } \\
\text { defendida en } \\
24-10-58\end{array}$ \\
\hline 959 & LERNER, Natán & La protección de las minorías. & $\begin{array}{c}\text { Tesis } \\
\text { defendida en }\end{array}$ \\
\hline
\end{tabular}

de Fanelli. "El sector privado de la educación superior políticas públicas y sus resultados recientes en cinco países de América Latina." Buenos Aires: Centro de Estudios de Estado y Sociedad. 1993.

${ }^{30}$ Especialización en Administración de Justicia; Especialización en Derecho Administrativo y Administración Pública; Especialización en Derecho Ambiental; Especialización en Derecho Bancario; Especialización en Derecho de Daños; Especialización en Derecho de Familia; Especialización en Derecho y Política de los Recursos Naturales y del Ambiente; Especialización en Derecho Informático; Especialización en Derecho Internacional de los Derechos Humanos; Especialización en Derecho del Trabajo; Especialización en Derecho Penal; Especialización en Derecho Procesal Civil; Especialización en Derecho Procesal Civil (Modalidad intensiva); Especialización en Derecho Tributario; Especialización en Elaboración de Normas Jurídicas; Especialización en la Estructura Jurídico-Económica de la Regulación Energética; Especialización Interdisciplinaria en Problemáticas Infanto-Juveniles; Especialización en Derecho Constitucional; Especialización en Derecho de Salud y Responsabilidad Médica; Con convenios dictados en el Colegio Público de Abogados de San Isidro; Especialización en Derecho Tributario.

${ }^{31}$ Derecho Comercial y de los Negocios; Derecho y Economía; Filosofía del Derecho; Relaciones Internacionales; Derecho Internacional de los Derechos Humanos; Magistratura; Derecho Penal del MERCOSUR; Derecho de Familia, Infancia y Adolescencia; Derecho Internacional Privado; Traducción e Interpretación; Problemáticas Sociales Infanto-Juveniles; Derecho Administrativo y Administración Pública; Interdisciplinaria en Energía; Derecho Penal y Derecho del Trabajo.

${ }^{32}$ Areas del doctorado: Derecho Administrativo; Derecho Aeronáutico y Espacial; Derecho Agrario y Minero; Derecho Civil; Derecho Comparado;Derecho Constitucional; Derecho de Transporte y Tránsito; Derecho Financiero; Derecho Fiscal; Derecho Internacional; Derecho Laboral; Derecho Marítimo; Derecho Mercantil; Derecho Notarial; Derecho Penal; Derecho Político; Derecho Procesal; Derecho Romano; Derecho Social; Filosofía del Derecho; Historia del Derecho. 


\begin{tabular}{|c|c|c|c|}
\hline & & & $23-04-59$ \\
\hline 007 & $\begin{array}{c}\text { CANET, Lilia } \\
\text { Viviana }\end{array}$ & Sobre el marco constitucional de los Pueblos Indígenas. & $\begin{array}{c}\text { Tesis } \\
\text { defendida en } \\
\text { 09-05-07 }\end{array}$ \\
\hline 007 & $\begin{array}{l}\text { GONZÁLEZ, } \\
\text { Ricardo Oscar }\end{array}$ & Proyección Social de los Pueblos Originarios. & $\begin{array}{c}\text { Tesis } \\
\text { defendida en } \\
\text { 18-07-07 }\end{array}$ \\
\hline 011 & $\begin{array}{l}\text { CARRASCO, } \\
\text { Nélida Ángela }\end{array}$ & $\begin{array}{c}\text { Derecho a la identidad: organización comunitaria y territorio } \\
\text { indígena. Estúdio de caso: Lhaka Honhat contra el Estado } \\
\text { Argentino }\end{array}$ & $\begin{array}{c}\text { Tesis } \\
\text { defendida en } \\
\text { 18-07-07 }\end{array}$ \\
\hline 014 & $\begin{array}{l}\text { Silvina del Valle } \\
\text { Ramírez }\end{array}$ & $\begin{array}{c}\text { Matriz Constitucional, Estado Intercultural y Pueblos } \\
\text { Indígenas en Argentina }\end{array}$ & $\begin{array}{c}\text { Tesis } \\
\text { defendida en } \\
\text { 14-04-14 }\end{array}$ \\
\hline 015 & $\begin{array}{c}\text { Adriana Victoria } \\
\text { Rodríguez Caguana }\end{array}$ & $\begin{array}{l}\text { Los derechos lingüísticos y culturales de los pueblos indígenas } \\
\text { del Ecuador. Antecedentes y vinculación con la legislación } \\
\text { internacional de derechos humanos 1944-2014 }\end{array}$ & $\begin{array}{c}\text { Tesis } \\
\text { defendida en } \\
\text { 03-12-15 }\end{array}$ \\
\hline
\end{tabular}

Tabela elaborada pelos autores. Fonte: Acervo de Teses - Universidade de Buenos Aires - Faculdade de Direito, 2016.

\section{COMUNIDADES NATIVAS NO PERU: REFLEXÕES SOBRE A PRODUÇÃO CIENTÍFICA ${ }^{33}$}

A educação superior no Peru é ministrada em escolas e institutos superiores, centros superiores de pósgraduação e universidades. Os institutos oferecem programas de formação de professores e uma vasta lista de opções na formação técnica em cursos que têm uma duração não inferior a quatro nem superior a dez semestres acadêmicos. Os institutos e escolas superiores outorgam títulos de profissional, técnico e perito e também os de segunda especialização profissional e ulterior. As universidades outorgam títulos de licenciado, mestre e doutor, bem como certificados e títulos profissionais, inclusivamente os de segunda especialização e ulterior. (PERU: MINISTERIO DE EDUCACIÓN, 2015)

No tocante aos recursos que subsidiam as instituições de Educação Superior atualmente o acompanhamento é realizado pelo Conselho de Reitores (2015). ${ }^{34}$ Esse normatiza e fiscaliza as principais ações de financiamento, que geralmente circulam ao redor dos projetos de pesquisa (Livre Concorrência - através de Edital), bolsas de ensino e crédito educativo - com regras específicas para cada Instituição Superior (Pública e Privada), sendo que podem se beneficiar alunos da rede pública e privada. (PERU: MINISTERIO DE EDUCACIÓN, 2015)

\footnotetext{
${ }^{33}$ Segundo dados do Ministério de Educação, o sistema educativo peruano divide-se em: Educação básica ou inicial; Educação primária; Educação secundária e Educação superior.

${ }^{34} \mathrm{O}$ governo central não intervém diretamente no sistema de educação superior universitário. As universidades peruanas têm autonomia universitária, sendo este o princípio fundamental que garante a sua independência relativamente aos poderes públicos na tomada de decisões dentro do âmbito das suas competências. Destina-se à Assembleia Nacional de Reitores atribuições normativas, de coordenação e de controle de qualidade ao ensino superior.
} 
Segundo dados do Conselho de Reitores (2015), há 3 modalidades de atribuição dos recursos públicos às universidades públicas:

1. Tesouro Público: atribui-se com base em planilhas orçamentárias apresentadas por cada universidade à Comissão de Orçamento do congresso. Não são considerados indicadores de gestão, mérito ou outros indicadores classificatórios;

2. Cânone, sobrecânone, regalias, rendimentos alfandegários e participações: O governo regional apoia o financiamento das universidades com base nos projetos de investimento apresentados e aprovados pelo Sistema Nacional de Investimento Público (SNIP), levando em consideração a adesão as políticas de Desenvolvimento Regional;

3. Conselho Nacional de Ciência e Tecnologia: Apoia o financiamento de projetos de pesquisa e extensão - baseados essencialmente na produção coletiva de áreas em Programas de Graduação e PósGraduação, somados aos resultados obtidos por meio da eficácia de indicadores anteriores.

Dentre as principais Universidades Públicas situadas na capital - Lima - pode-se citar: a Universidad Nacional del Callao (UNAC) (Bellavista); Universidad Nacional Mayor de San Marcos (UNMSM) (El Cercado) ${ }^{35}$; Universidad José Faustino Sánchez Carrión (UNJFSC) (Huacho); Universidad Nacional Agraria La Molina (La Molina); Universidad Nacional de Educación E. Guzmán y Valle (UNE) (Lima); Universidad Nacional de Ingeniería (UNI) (Rimac); Universidad Nacional Federico Villarreal (UNFV) ${ }^{36}$ (San Miguel); Instituto Superior Tecnológico Público Antenor Orrego Espinoza (Chorrillos); Instituto Superior Tecnológico Público Argentina (Lima); Instituto Superior Tecnológico Público Diseño y Comunicación (IDC) (Lima); Instituto Superior Tecnológico Púb. Juan Velasco Alvarado (V. María del Triunfo); Instituto Superior Tecnológico Público Julio César Tello (Villa El Salvador); Instituto Superior Tecnológico Público Naciones Unidas (Pueblo Libre); Instituto Superior Tecnológico Público Ramiro Priale (Lurigancho); Instituto Superior Tecnológico Público Villa María (Villa María del Triunfo); Instituto Superior Pedagógico Público de Educación Inicial (Lima) e Instituto Superior Pedagógico Púb. Manuel González Prada (Villa el Salvador).

$\mathrm{Na}$ Universidade Nacional Mayor de San Marcos ${ }^{37}$ (UNMSM), o Programa de Pós-Graduação em Direito está integrado com as Ciências Políticas. Segundo dados acadêmicos e históricos da instituição:

\footnotetext{
${ }^{35}$ Trata-se de uma universidade pública com sede em Lima. Atualmente é a principal instituição de ensino do país. Também é oficialmente a primeira universidade peruana e a mais antiga do continente americano.

${ }^{36}$ Nessa Universidade encontra-se a produção de três trabalhos tendo como indicação a temática 'Comunidades Indígenas. São eles: Estructuración de un SDSS para la comunidad indígena Boca Pariamanu - Madre de Dios. Lima,2007, escrita por Guerrero Medianero, Guillermo Miguel; La reducción indígena del Cercado. Lima,1972, de Cardenas Ayaipoma, Mario e Religión indígena colonial en Canta, Chancay y Cajatambo. Lima, 1970 com autoria de Huertas Vallejo, Lorenzo.

${ }^{37}$ Em seus mais de 450 anos, a instituição formou diversos personagens que se destacaram no contexto latino-americano, dentre os quais estão: Santiago Antúnez de Mayolo; José María Arguedas; Jorge Basadre; Alfredo Bryce Echenique; Daniel Alcides Carrión; Honorio Delgado; Alan García; Gustavo Gutiérrez; Víctor Raúl Haya de la Torre; Cayetano Heredia; Luis Alberto Sánchez; Julio vol.10, nº. 01, Rio de Janeiro, 2017.pp. 149-177 168
} 
La historia de la facultad de derecho está intimamente relacionada con la historia de creación de la Universidad. Luego de crearse por Real Cédula del 12 de Mayo de 1551, expedida en Valladolid por la Reina Doña Juana, hija de los Reyes Católicos y Madre de Carlos V, con el nombre de Real y Ponteficia Universidad de San Marcos. El Virrey del Perú García Hurtado de Mendoza fundó dentro de la Universidad el Colegio Real Felipe, destinado a la enseñanza de la leyes. En sus inicios la Universidad funcionó en el Convento de Santo Domingo, posteriormente, en San Marcelo y a partir de 1577 durante toda la época de la Colonia junto a la llamada Plaza de la Inquisición. En 1770, se fundó el histórico Colegio de San Carlos, fusionando los Colegios de San Felipe (Derecho) y San Martín (Filosofía y Letras). El 07 de Abril de 1855 el presidente Don Ramón Castilla promulgó un Decreto Supremo por el cual establecía que las Facultades de Jurisprudencia, Matemática y Ciencias Naturales funcionará en el Colegio de San Carlos y la Facultad de Medicina en la Escuela que lleva ese nombre. En 1861 la universidad se traslada a los claustros del antiguo noviciado de Jesuítas a la Iglesia de San Carlos, lo que hoy es el Panteón de los Próceres de la República. En 15 de Marzo de 1866, el General Mariano Ignacio Prado, dictó un Decreto Supremo mediante el cual el Convictorio de San Carlos se destinaría exclusivamente a las Facultades de Jurisprudencia, Ciencias y Letras; cada una de ellas será dirigida por un Decano nombrado por el gobierno. Por ley del Congreso del 29 de Agosto 1887 se suprimieron en todas las Universidades de la República el grado de Licenciado en Derecho. Con esta estructura culminó el siglo XIX y se intresó al presente siglo. Posteriormente, la Facultad de Jurisprudencia se transformó en la Facultad de Derecho. Los títulos que otorgaba la Facultad eran de Abogado, y los grados de Bachiller y Doctor en Derecho. No siglo XX, en 1935, el Presidente de la República General dieron un nuevo Estatuto Universitario para el funcionamiento de la Universidad de San Marcos, despues de haber sido clausurada por tres años, denominándose en el nuevo Estatuto a la Facultad de Derecho, Facultad de Derecho y Ciencia Política, como hasta la fecha se le conoce. (UNMSM, Dados históricos, 2016)

O programa de Pós-Graduação em Direito da Universidade de San Marcos possui um curso de doutorado e um mestrado. Essas duas modalidades possuem diversas linhas de pesquisa, dentre eles: Ciência Penal, Direito Civil e Comercial, Direito do Trabalho e da Seguridade Social, Direito Constitucional e Direitos Humanos, Direito Processual, Direito Empresarial e Tutela dos Direitos, Globalização da Justiça e Estado Constitucional. (UNMSM, Dados Acadêmicos. Faculdade de Derecho, 2016).

Em análise a produção científica a Faculdade de Direito através do Programa de Pós-Graduação a UNMSM encontra-se em domínio público um total de 164 teses (Mestrado e Doutorado), sendo 51 em nível de doutorado e 113 na categoria Mestrado. Dessas 13 tiveram como objeto de estudo as comunidades nativas e os povos indígenas conforme a tabela abaixo.

Tabela 3 - Teses aprovadas - UNMSM - Programa de Pós-Graduação em Direito (1892 2015)

\begin{tabular}{|c|c|c|}
\hline \multicolumn{2}{|c|}{ Temática indígenas e comunidades tradicionais } \\
\hline no & Autor/a & Título \\
\hline 892 & $\begin{array}{c}\text { Oyague, Carlos } \\
\text { Alberto }\end{array}$ & La Civilización del Pueblo Indio \\
\hline
\end{tabular}

C. Tello; Hipólito Unanue; Abraham Valdelomar; César Vallejo, um dos principais poetas do século XX; Mario Vargas Llosa (Nobel prize medal.svg Nobel de Literatura 2010) e Federico Villarreal. 


\begin{tabular}{|c|c|c|}
\hline 005 & Taipe Sánchez, Carlos & $\begin{array}{l}\text { Coexistencia conflictiva entre el derecho oficial y los pueblos indígenas en el } \\
\text { Perú: comunidad indígena Kechua de Talwis-Huancavelica }\end{array}$ \\
\hline 006 & $\begin{array}{l}\text { Pablo Huacausi, } \\
\quad \text { Mario }\end{array}$ & $\begin{array}{l}\text { Actitud hacia la religión en miembros de la comunidad autogestionaria de } \\
\text { Huaycán }\end{array}$ \\
\hline 006 & $\begin{array}{l}\text { Arroyo Aguilar, } \\
\quad \text { Sabino }\end{array}$ & $\begin{array}{l}\text { Culto a los Hermanos Cristo. Sistema religioso andino y cristiano: redes y } \\
\text { formas culturales del poder en los andes }\end{array}$ \\
\hline 007 & $\begin{array}{l}\text { Torrejon Pizarro, } \\
\text { Elmer Antonio }\end{array}$ & $\begin{array}{c}\text { El mundo religioso de los Luya y Chillaos. Un análisis contemporáneo en los } \\
\text { pueblos de la provincia de Luya - Amazon }\end{array}$ \\
\hline 011 & Huaco Pastor, Enrique & $\begin{array}{l}\text { El Diseño organizacional de la municipalidad distrital y la propuesta de un } \\
\text { modelo alternativo con producción de servicios con estándares de } \\
\text { productividad satisfactorios (caso: Municipalidad Distrital de Pueblo Libre) }\end{array}$ \\
\hline 012 & $\begin{array}{l}\text { Carhuatocto } \\
\text { Sandoval, Henry Oleff }\end{array}$ & $\begin{array}{l}\text { Los Derechos constitucionales de los pueblos indígenas en aislamiento } \\
\text { voluntario y en contacto inicial en el sector de hidrocarburos en el Perú }\end{array}$ \\
\hline 012 & $\begin{array}{l}\text { Miranda Saucedo, } \\
\text { Tomas Francisco }\end{array}$ & $\begin{array}{l}\text { Posibilidades y limitaciones de la educación Intercultural Bilingüe en Bolivia y } \\
\text { Perú }\end{array}$ \\
\hline 013 & Tipula, Pedro & Dilemas Territoriales: Comunidad Nativa, Estado y Empresas Extractivas \\
\hline 014 & $\begin{array}{l}\text { Díaz Bravo, José } \\
\text { Alejandro }\end{array}$ & $\begin{array}{l}\text { Organización, participación y visión de desarrollo en } 35 \text { comunidades del } \\
\text { distrito del Pueblo Nuevo, Chincha }\end{array}$ \\
\hline 014 & Itusaca Condori, Silvia & $\begin{array}{l}\text { Construcción de la ciudadanía aimara en la región Puno: conflicto de Ilave } \\
\qquad(2004)\end{array}$ \\
\hline 014 & Vidal Alegría, Liliana & $\begin{array}{l}\text { Pie plano y su relación con la postura pelvica en escolares del Instituto } \\
\text { Educativo Primaria República de Irlanda - Distrito de Pueblo Libre. }\end{array}$ \\
\hline 015 & $\begin{array}{l}\text { Ríos Indacochea, } \\
\text { Candelaria De La } \\
\quad \text { Soledad }\end{array}$ & Participación y representación legislativa de afroperuanos e indígenas \\
\hline
\end{tabular}

Tabela elaborada pelos autores. Fonte: Acervo de Teses - Universidade Nacional Mayor de San Marcos - Faculdade de Direito, 2016.

Em nível de ensino superior na categoria ensino privado elenca-se a Universidad Cesar Vallejo (UCV); Universidad Católica Sedes Sapientiae (UCSS) (Los Olivos); Universidad Privada del Norte (UPNORTE) (Los Olivos); Universidad Científica del Sur (UCSUR) (Miraflores); Universidad Peruana Unión (UPEU) (Ñaña); Universidad Antonio Ruiz de Montoya (UARM) (Pueblo Libre); Universidad de Piura (PAD) (San Isidro); Universidad Peruana Cayetano Heredia (UPCH) (San Martín de Porres) e Pontificia Universidad Católica del Perú (PUCP) (San Miguel). A PUCP foi escolhida para esse estudo comparativo devido a sua trajetória histórica - anos de funcionamento e reconhecimento acadêmico. Também existem Universidades nas províncias de Ancash, Apurimac, Ayacucho, Arequipa, Cajamarca, Cusco, Huancavelica, Huanuco, Junín, Ica, Loreto, La Libertad, Lambayeque, Moquegua, Pasco, Piura, Puno, San Martín, Tacna, Tumbes e Ucayali. (PERU: MINISTERIO DE EDUCACIÓN, 2015)

\section{Sobre a PUCP}

A Pontifícia Universidade Católica do Peru foi criada em 1917 com duas faculdades, Letras e vol.10, nº. 01, Rio de Janeiro, 2017.pp. 149-177 
Jurisprudência. Seu primeiro diretor foi R. P. Jorge Dintilhac SS.CC. Entretanto, o estado a reconheceu oficialmente em 24 de março de 1917 por meio de uma Resolução Suprema. Através da lei n ${ }^{\circ} 11003$ de 17 de Abril de 1949, e no 13.417, de 8 de abril de 1960, obteve autonomia pedagógica depois de receber um prêmio científico e adquirir visibilidade social. (PUCP, Historia, 2016)

Muitas foram às contribuições prestadas à ciência pela Pontifícia Universidade Católica - PUCP considerando que a mesma atua com Ensino, Pesquisa e Extensão e possui reconhecimento em nível nacional e internacional. Segundo Rosales (2013, p.6),

En la actualidad nuestro país enfrenta una serie de conflictos sociales entre las comunidades campesinas y/o nativas, las empresas dedicadas a la extracción de recursos naturales (minerales, especies acuáticas, hidrocarburos, árboles, etc.) y el Estado. Estos enfrentamientos exigen respuestas desde las distintas disciplinas, siendo la jurídica tal vez no la más importante pero si la típicamente eficaz para resolver dichos problemas. Esta postura propositiva, si bien no la única, constituye la motivación principal del presente trabajo. En comparación con otros países, en el Perú, la discusión académica sobre estos temas es algo tardía. Uno de los factores de dicha demora respondería a las experiencias de dictaduras militares que gobernaron durante décadas en la región y, en particular, en nuestro país. Recordemos que, en su mayoría, los regímenes militares proclaman, a partir de un poder autoritario, una sociedad igualitaria. Por ello, el Estado no se percata de las diferencias (culturales o lingüísticas) que existen en las personas que conforman la población.

A pesquisa realizada junto ao acervo de teses da PUCP - área de Direito, em nível de Pós-Graduação -

foi possível identificar apenas 05 trabalhos que envolvem a temática comunidades nativas e os povos indígenas conforme a tabela abaixo.

Tabela 4 - Teses aprovadas - PUCP (1990 - 2015)

\begin{tabular}{|c|c|c|c|}
\hline \multicolumn{4}{|c|}{ Temática indigenas e comunidades tradicionais } \\
\hline $\mathrm{n}^{\mathrm{o}}$ & Autor/a & Título & Área \\
\hline 015 & $\begin{array}{l}\text { Nancy } \\
\text { Milagros } \\
\text { Ortega } \\
\text { Vásquez }\end{array}$ & $\begin{array}{l}\text { El derecho de propiedad comunal indígena en la amazonía y su } \\
\text { regulación en la legislación peruana }\end{array}$ & Derecho Civil \\
\hline 014 & $\begin{array}{l}\text { Gerard henry } \\
\text { Angels Yanqui }\end{array}$ & $\begin{array}{l}\text { Naturaleza y alcance constitucional del consentimiento en el } \\
\text { derecho a la consulta previa a los pueblos indígenas, en los } \\
\text { casos de desplazamiento de territorio }\end{array}$ & $\begin{array}{c}\text { Derecho } \\
\text { Constitucional }\end{array}$ \\
\hline 013 & $\begin{array}{l}\text { Paola Brunet } \\
\text { Ordoñez } \\
\text { Rosales }\end{array}$ & $\begin{array}{l}\text { El derecho a ala educación intercultural bilíngue (EIB) de las } \\
\text { Comunidades Nativas del Perú }\end{array}$ & $\begin{array}{c}\text { Derecho } \\
\text { Constitucional }\end{array}$ \\
\hline 012 & $\begin{array}{l}\text { Valérie } \\
\text { Gosselin }\end{array}$ & $\begin{array}{l}\text { Los efectos del multiculturalismo federal y del } \\
\text { interculturalismo quebequense sobre el derecho a recibir } \\
\text { educación primaria y secundaria en el propio idioma en la } \\
\text { provincia de Quebec en Canadá }\end{array}$ & $\begin{array}{l}\text { Tesis de maestría en } \\
\text { Derechos Humanos }\end{array}$ \\
\hline 011 & $\begin{array}{l}\text { Diego García- } \\
\text { Sayá }\end{array}$ & Derechos de los pueblos indígenas y justicia interamericana & $\begin{array}{l}\text { Tesis de maestría en } \\
\text { Derechos Humanos }\end{array}$ \\
\hline
\end{tabular}

Tabela elaborada pelos autores. Fonte: Repositorio Digital de Tesis/PUCP- Faculdade de Direito, 2016. 
Também é necessário registrar a presença de quase uma dezena de trabalhos de conclusão de Curso em nível da Graduação que estudam a temática comunidades indígenas, dentre eles: Artes, Ciências Políticas, Ciências Sociais, Educação e Letras. No campo jurídico, os estudos se concentram basicamente na área de Direito Civil e Constitucional. Enquanto procedimento metodológico os trabalhos analisados assentam-se comumente na pesquisa bibliográfica. Como exemplo cita-se o trabalho realizado sob o título "Discriminación vs. exclusión: análisis de la brecha de ingresos por áreas geográficas entre la población indígena y no indígena”

Há também pesquisas com o tema populações indígenas ou comunidades tradicionais nas áreas de Antropologia, Ciências Políticas (Mestrado e Doutorado), com foco em Estudos de Gênero ${ }^{38}$, História, Serviço Social e Sociologia. A pesquisa identificou um total de 75 trabalhos. ${ }^{39}$ À guisa de exemplo pode-se indicar a dissertação escrita por Aída Mercedes Gamboa Balbín, apresentada a banca avaliadora em 2014 a qual possui como título "Las demandas indígenas en el conflicto socioambiental hidrocarburífero entre el pueblo indígena amazónico Quechua del Pastaza y la empresa Pluspetrol Norte entre los años 2012 y 2013”.

Segundo a tesista, a devida pesquisa tem como questionamento central:

¿Cómo se construyen las demandas indígenas en el conflicto socioambiental hidrocarburifero entre el pueblo indígena amazónico Quechua del Pastaza y la empresa Pluspetrol Norte? De esta pregunta se desprenden los 3 sub objetivos planteados: (i) describir a los actores y sus demandas, (ii) comprender el desarrollo de la estructura de oportunidad política y los recursos movilizadores en la movilización indígena y (iii) determinar los procesos de "encuadre" del discurso político indígena en la movilización. Este caso es un ejemplo de los conflictos que tienen como elemento la superposición de lotes de hidrocarburos en territorios indígenas, lo que ha originado intereses divergentes entre pueblos indígenas amazónicos y empresas petroleras, donde el Estado es el supuesto mediador de las confrontaciones y garantista de sus derechos. Sin embargo, son los pueblos indígenas los actúan colectivamente para exigir demandas mínimas y concretas al Estado, construyendo una serie de acciones a partir de una estructura de oportunidad política poco exitosa a nivel nacional y regional, fuertes recursos de movilización y el uso de discursos legitimados a través de hechos concretos, que combina el paradigma multicultural con el paradigma de la igualdad. Así, se generan movimientos indígenas como el dirigido por el pueblo Quechua del Pastaza en Loreto que ha sido afectado por impactos ambientales y sociales tras 40 años de contaminación petrolera en sus territorios. De modo que, la construcción de las demandas indígenas estaría ligada al inefectivo rol que cumple el Estado para garantizar el respeto por sus formas de desarrollo, el ejercicio de sus derechos fundamentales como colectivos y la adecuada fiscalización de impactos negativos generados por los proyectos de inversión de hidrocarburos. (BALDIN, 2014. p.9)

\footnotetext{
${ }^{38} \mathrm{~A}$ exemplo indica-se a dissertação de Eduardo Miguel Huaytán Martínez, sob o título "Testimonio de mujeres en el Perú (19741979):inicios, cambios, diferencias y límites representacionales." Esta tesis aborda el testimonio de mujeres en el Perú, en particular los testimonios de Agustina Huaquira Mamani (1974), Asunta Quispe Huamán (1977) y los testimonios colectivos de Ser mujer en el Perú (1977) y Cinturón de castidad (1979).

${ }^{39}$ Vide título e resumo dos trabalhos em http://tesis.pucp.edu.pe/repositorio/
} 


\section{CONCLUSÃO}

A modernidade foi à idade da hegemonia europeia sobre diversos países do mundo à custa das relações de poder advindas do controle das formas de produção econômica (trabalho e recursos naturais), de construção do conhecimento (ciência como única forma legítima de saber) e hierarquização das identidades subjetivas (raça e gênero como elementos centrais de negação de humanidade). Através da égide do colonialismo as relações de poder e violência tangenciam a contemporaneidade.

Segundo dados da ONU/Banco Mundial em Brasília (2015), os nativos representam 8\% da população latino-americana, sendo que a pobreza afeta $43 \%$ destes, ou seja, mais que o dobro da proporção de não indígenas. Além disso, o percentual de ameríndios que vivem em extrema pobreza representa um número 2,7 vezes maior que o encontrado no restante da população. Justificando nessa perspectiva a necessidade cada vez mais intensa da integração universidade com os temas e problemas que circundam a sociedade de um modo geral.

Nesse aspecto, outro elemento que tange as comunidades nativas diz respeito a alguns avanços observados nas duas últimas décadas - especialmente ao acesso à educação e à infraestrutura, bem como na participação política. Entretanto, com pouca incidência enquanto a redução na desigualdade. No Brasil, por exemplo, atualmente, os indígenas constituem $14 \%$ dos pobres e 17\% dos extremamente pobres da América Latina. Estudiosos das questões indígenas na América Latina apontam para a ressignificação do ethos das comunidades nativas, e construindo novas estratégias para seus saberes, conhecimento e cultura. Isso possibilita a apresentação de suas demandas ao Estado e o reconhecimento de sua existência enquanto pessoas dotadas de dignidade humana, detentoras de cultura própria, fazendo valer assim os seus direitos.

Enquanto análise da produção científica junto aos Programas de Pós-Graduação em Direito, foi possível observar de forma horizontalizada no decorrer desse trabalho que a tônica das teses está centrada essencialmente nas políticas ligadas à conquista dos nativos por vez e voz dentro do campo indigenista brasileiro e latinoamericano, da reconquista das terras pelos nativos - avanços e retrocessos, da ampliação de suas organizações socioculturais e identitárias, do fortalecimento dos vínculos com a terra, interculturalização e reflexo das legislações nacionais e internacionais na nova codificação dos povos indígenas. Enquanto conclusão, a maioria dos estudos indicam para a necessidade das novas ações provocarem e 'realizarem' a recusa minimização das comunidades indígenas, especialmente quando se constata o quadro de omissão dos poderes públicos, que se negam a cumprir as Constituições no que tange a demarcação das terras e a violência física e etno-cultural na América Latina.

Nas Universidades pesquisadas foi possível identificar os primeiros trabalhos de investigação junto às universidades peruanas (Universidade Nacional Mayor de San Marcos) com 13 trabalhos defendidos na Universidade San Marcos e outros na Pontifícia Universidade Católica, sendo a maior concentração nas áreas de 
Ciências Humanas e Sociais. A universidade brasileira escolhida para esse ensaio figura como protagonista por possuir registro de 16 trabalhos na área de Direito em nível de Pós-Graduação. Posterior temos a UBA - Pósgraduação em Direito com 07 trabalhos elaborados e defendido no período de (1958 - 2015). Foi possível também identificar diversos trabalhos de Pós-Graduação nas áreas de Antropologia, História, Geografia e Sociologia junto a Universidade de Buenos Aires.

Nesse cenário, pode-se apontar que as mudanças também são notadas no cenário político internacional através da eleição de alguns presidentes nativos e ou mestiços em países sul-americanos, como Evo Morales, na Bolívia, Rafael Correa, no Equador, e Hugo Chávez e Nicolas Maduro, na Venezuela. Todos eles promoveram, em alguma medida, mudanças constitucionais a fim de incluir políticas públicas para os povos indígenas. Buscaram também a redução da pobreza através da redistribuição de renda no país e pela instalação de programas de educação e saúde com maior amplitude. Além disso, constata-se também um aumento do número de partidos indígenas nesses países, o que significa que as comunidades indígenas estão se constituindo em um importante grupo de interesses.

Enquanto temática, sabe-se que sem a inclusão dessas vozes inaudíveis (indígenas) no patrimônio material e imaterial cultural da América Latina, não há possibilidade de discussão, de dialética, de exercício pleno da democracia, ou seja, de construção de um projeto político mais amplo, integral e universal. Nessa via, a população de racionalidade ocidental segue solitária, acreditando que pertence a ela a tarefa de velar pela diversidade cultural, fazendo respeitar as formas culturais através das quais ela vê o mundo. Assim, seguirá acreditando que o mundo é único e somente pode ser explicado pelo viés de quem o domina e explica.

\title{
SCIENTIFIC IDENTITY AND INDIGENOUS PEOPLES: COMPARATIVE PERSPECTIVES BETWEEN ARGENTINA, BRAZIL AND PERU (1950-2015)
}

\begin{abstract}
The present study aims, establish a comparative study between the scientific production in postgraduate courses in law, having as object the research and dissertations that have thematic analysis of indigenous peoples and traditional communities. They have been included for this purpose to the public University located in Argentina, Brazil and Peru, with the time limits for the period 1950-2015. The methodological procedure used is the analytical - interpretative research and analysis of current legislation, including in international documents, particularly the Convention No. 169 of the international organization of labour (ILO) concerning indigenous and tribal, as well as the field research in the following institutions: University of Buenos Aires / Argentina, Federal University of Santa Catarina / Brazil, Universidad Nacional Mayor de San Marcos / Pontifical University and Peru / Peru.
\end{abstract}

Keywords: Argentina; Brasil; Perú; Identidad; Poblaciones Nativas. Scientific Production. 


\section{REFERÊNCIAS BIBLIOGRÁFICAS}

BALÁN, Jorge Balán \& FANELLI, Ana M. García de Fanelli. El sector privado de la educación superior políticas públicas y sus resultados recientes en cinco países de América Latina. In: Buenos Aires: Centro de Estudios de Estado y Sociedad. Buenos Aires, 1993.

BUCHBINDER, PABLO. Historia de las Universidades Argentinas. Buenos Aires: Editorial Sudamericana, 2005.

BRASIL. Conselho Federal de Educação. Parecer no 977/65. Definição dos cursos de pós-graduação. Brasília, DF, 1965.

Ministério da Educação e Cultura. Plano Nacional de Pós-graduação no Brasil. Brasília, DF, 1975.

Coordenação de Aperfeiçoamento de Pessoal de Nível Superior. Reformulação do Sistema de Avaliação

da Pós-graduação: o modelo a ser implantado na avaliação de 1998 (documento em discussão). Brasília, DF: CAPES, 1996.

DEL, Enrique Percio M. A Condição Social: consumo, poder e representação no capitalismo tardío. Trad.: Ana Paula Cacho e Gustavo Borges. São Paulo: Editora Lexia, 2014.

FLECK, Eliane Cristina Deckmann. "A educação jesuítica nos Sete Povos das Missões (séculos 17-18)". In: Ministério da Educação do Brasil. Revista Em Aberto, 2009.

GARCIA, Elisa Frühauf. "Solução caseira". In: Revista de História, 01/04/2013.

GARCIAS FRANCO, J. S.: "El surgimiento del campo de la política educativa en Argentina: los casos de las universidades nacionales de Buenos Aires y La Plata”. In: Em Práxis Educativa, Ponta Grossa, v. 9, n. 2, jul. / dic. 2014, p. 461-484.

HAMBURGER, E. Para que pós-graduação? Encontros com a civilização brasileira. Rio de Janeiro: Civilização Brasileira, 1980.

HERRERA FLORES, Joaquín. Teoria Crítica dos Direitos Humanos: os direitos humanos como produtos culturais. Rio de Janeiro: Lumen Iuris, 2009

JUNQUEIRA, Carmen. The Brazilian Indigenous Problem and Policy: The Example of The Xingu National Park. In: AMAZIND/IWGIA Document. Copenhagen/Geneva, 1973.

LIMA, Luciana Alves de. Direito Socioambiental - Proteção da diversidade biológica e cultural dos povos Indígenas. Faculdade de Direito de Curitiba, 2009.

MOREIRA, Ruy. As categorias espaciais da construção geográfica das sociedades. In: Geographia, Niterói, v.3, n.5, p.16-34, 2001.

OIT. Convenção $n^{\circ} 169$ sobre povos indígenas e tribais e Resolução referente à ação da OIT / Organização Internacional do Trabalho. Brasilia: OIT, 2011.1 v.

QUIJANO, Aníbal. Cuestiones y horizontes: de la dependencia histórico-estructural a la colonialidad/descolonialidad del poder. Aníbal Quijano; selección a cargo de Danilo Assis Clímaco; con prólogo de Danilo Assis Clímaco. - 1a Ed. - Ciudad Autónoma de Buenos Aires: CLACSO, 2014. 
1992

Notas sobre a questão da identidade e nação no Peru. In: Revista estudos Avançados, São Paulo, v. 6 (16),

RIBEIRO, Darcy. Os índios e a civilização. Petrópolis: Vozes, 1977.

RODRIGUES, Horácio Wanderlei. Ensino do Direito no Brasil: Diretrizes Curriculares e Avaliação das Condições de Ensino. Florianópolis/SC: Fundação Boiteux, 2002.

ROMANELLI, O.O. História da educação no Brasil. 15a ed. Petrópolis: Vozes, 1993.

VARELLA, M. D. e BARRETO, M. M. Políticas de revalidação de diplomas de pós-graduação em Direito no Brasil: dificuldades e desafios para o sistema brasileiro. In: Revista Brasileira de Polítcas Públicas, v. 2, n. 1p. 143 161.

ZAFFARONI, E. Raúl. El Derecho latinoamericano en la fase superior del Colonialismo. In: Revista Pensar en derecho. FERREYRA, Raúl Gustavo. El principio de subordinación como fundamento del Estado constitucional. Su regulación en Argentina, Brasil, Colombia, Ecuador y México, 2014.

WEREBE, M.J.G. 30 anos depois: grandezas e misérias do ensino no Brasil. São Paulo: Ática, 1994.

\section{Fontes eletrônicas}

GALARDI, Veronica Lescano. Algunas propuestas de transformaciones educativas en la Argentina: reforma educativa de Saavedra Lamas. Disponível em: http://www.derecho.uba.ar/publicaciones/libros/pdf/facultadde-derecho-y-ciencias-sociales-ensenanza-de-su-historia. Acesso em 11/03/2016.

MEJÍA JIMÉNEZ, Marco Raúl. Las búsquedas del pensamiento propio desde el buen vivir-vivir bien y la educación popular. 2012. Disponível em: <https://rednelhuila.files.wordpress.com/2013/12/ponencia-buenvivir.pdf $>$.Acesso em: 12/02/2016.

ONU. Centro de informação das Nações Unidas. Disponível em http://www.unric.org/pt/actualidade/10163. Acesso em 31/01/2016.

PERU. Ministerio de Educación. Disponível em 21/02/2016. http://www.minedu.gob.pe/. Acesso em 12/02/2016.

PUCP. Espacio de memoria. Disponível em http://www.pucp.edu.pe/la-universidad/nuestrauniversidad/historia/resena-historica/. Acesso em 21/02/2015.

SANTOS, Cassio Miranda dos. Tradições e Contradições da Pós-Graduação no Brasil. In: Revista Educaçao e Sociedade. Campinas, vol. 24, n. 83, p. 627-641, agosto 2003. Disponível em <http://www.cedes.unicamp.br. Acesso em 16/02/2016.

UNIVERSIDADE DE BUENOS AIRES. Dados e Informações. Faculdade De Derecho. http://www.uba.ar/institucional/contenidos.php?idm=120. Acesso em 17/02/2016.

UNIVERSIDADE DE BUENOS AIRES. Programa Historia y memoria: 200 años de la Uba. Secretaria de assuntos académicos. http://www.uba.ar/historia/contenidos.php?id=1\&s=10. Acesso em 17/02/2016. 
UNIVERSIDADE FEDERAL DE SANTA CATARINA (UFSC). Curso de Graduação em Direito: Projeto Pedagógico (2004). Disponível em: < http://ccj.ufsc.br/files/2014/09/Curr\%C3\%ADculoDirUFSC-2004projetopedag\%C3\%B3gico.pdf $>$. Acesso em: 19/02/16.

UNIVERSIDAD NACIONAL MAYOR DE SAN MARCOS. Dados institucionales y historicos. Disponível em http://derecho2.unmsm.edu.pe/index.php?id=facultad. Acesso em 21/02/16.

Trabalho enviado em 06 de outubro de 2016.

Aceito em 06 de outubro de 2016. 